\title{
A Novel Interaction of Translocator Protein 18 kDa (TSPO) with NADPH Oxidase in Microglia
}

\author{
Meredith K. Loth ${ }^{1}$ - Sara R. Guariglia ${ }^{1}$ - Diane B. Re ${ }^{1}$ - Juan Perez ${ }^{2}$ - Vanessa Nunes de Paiva ${ }^{2}$ • Jennifer L. Dziedzic ${ }^{2}$. \\ Jeremy W. Chambers ${ }^{2}$. Diana J. Azzam ${ }^{2} \cdot$ Tomás R. Guilarte $^{1,2}$ [1]
}

Received: 19 December 2019 / Accepted: 24 July 2020 / Published online: 2 August 2020

(C) The Author(s) 2020

\begin{abstract}
In the brain neuropil, translocator protein $18 \mathrm{kDa}$ (TSPO) is a stress response protein that is upregulated in microglia and astrocytes in diverse central nervous system pathologies. TSPO is widely used as a biomarker of neuroinflammation in preclinical and clinical neuroimaging studies. However, there is a paucity of knowledge on the function(s) of TSPO in glial cells. In this study, we explored a putative interaction between TSPO and NADPH oxidase 2 (NOX2) in microglia. We found that TSPO associates with gp9 $91^{\text {phox }}$ and $\mathrm{p} 22^{\text {phox }}$, the principal subunits of NOX2 in primary murine microglia. The association of TSPO with gp9 $1^{\text {phox }}$ and $\mathrm{p} 22^{\text {phox }}$ was observed using co-immunoprecipitation, confocal immunofluorescence imaging, and proximity ligation assay. We found that besides $\mathrm{gp} 91^{\text {phox }}$ and $\mathrm{p} 22^{\text {phox }}$, voltage-dependent anion channel (VDAC) also coimmunoprecipitated with TSPO consistent with previous reports. When we compared lipopolysaccharide (LPS) stimulated microglia to vehicle control, we found that a lower amount of gp91 ${ }^{\text {phox }}$ and $\mathrm{p} 22^{\text {phox }}$ protein co-immunoprecipitated with TSPO suggesting a disruption of the TSPO-NOX2 subunits association. TSPO immuno-gold electron microscopy confirmed that TSPO is present in the outer mitochondrial membrane but it is also found in the endoplasmic reticulum (ER), mitochondriaassociated ER membrane (MAM), and in the plasma membrane. TSPO localization at the MAM may represent a subcellular site where TSPO interacts with gp $91^{\text {phox }}$ and $\mathrm{p} 22^{\text {phox }}$ since the MAM is a point of communication between outer mitochondria membrane proteins (TSPO) and ER proteins ( $\mathrm{gp} 91^{\text {phox }}$ and p22 ${ }^{\text {phox }}$ ) where they mature and form the cytochrome $b_{558}\left(C_{y t b}{ }_{558}\right)$ heterodimer. We also found that an acute burst of reactive oxygen species (ROS) increased TSPO levels on the surface of microglia and this effect was abrogated by a ROS scavenger. These results suggest that ROS production may alter the subcellular distribution of TSPO. Collectively, our findings suggest that in microglia, TSPO is associated with the major NOX2 subunits gp9 $1^{\text {phox }}$ and $\mathrm{p} 22^{\text {phox }}$. We hypothesize that this interaction may regulate Cytb $_{558}$ formation and modulate NOX2 levels, ROS production, and redox homeostasis in microglia.
\end{abstract}

Keywords TSPO $\cdot$ NOX2 $\cdot$ Microglia $\cdot$ Heme $\cdot$ ROS $\cdot$ Redox homeostasis

Electronic supplementary material The online version of this article (https://doi.org/10.1007/s12035-020-02042-w) contains supplementary material, which is available to authorized users.

Tomás R. Guilarte

tguilart@fiu.edu

1 Department of Environmental Health Sciences, Mailman School of Public Health, Columbia University, New York, NY, USA

2 Department of Environmental Health Sciences, Robert Stempel College of Public Health \& Social Work, Florida International University, Miami, FL 33199, USA

\section{Introduction}

Translocator protein $18 \mathrm{kDa}$ (TSPO) is a widely used preclinical and clinical biomarker of brain injury and neuroinflammation that is able to detect diverse brain pathologies [1-3]. The cellular framework for using TSPO as a biomarker is based on the activation of microglia and astrocytes, the glial cell types that express and upregulate TSPO levels following nervous system insults and neuroinflammation $[1,3,4]$. TSPO expression is nearly undetectable in the normal brain neuropil but increases markedly and selectively at primary and secondary sites of brain injury and neuroinflammation $[1,3]$. More specifically, TSPO has been used as a sensitive biomarker of reactive gliosis and inflammation associated with a variety of 
brain insults including chemical-induced neurotoxicity [5-10], ischemia [11], traumatic brain injury [12, 13], and a number of neurodegenerative disorders with an inflammatory component such as Alzheimer's disease, Parkinson's disease, amyotrophic lateral sclerosis (ALS), multiple sclerosis, and virus-induced neuroinflammation [14-18]. In this way, TSPO can be used to evaluate the neurotoxic potential of chemicals and to track active neuroinflammation and brain injury in a multitude of neurological and neurodegenerative conditions in humans using positron emission tomography imaging $[1,3]$.

Despite the extensive use of TSPO in preclinical and clinical neuroimaging studies to detect glial cell activation as a result of brain injury and neurodegeneration, the function of TSPO in glial cells has received limited attention, and studies on the function of TSPO in primary microglia or astrocytes are lacking. During the last several decades, a number of diverse functions have been attributed to TSPO, including cholesterol transport into the mitochondria for steroidogenesis; regulation of the mitochondrial permeability transition pore (mPTP); reactive oxygen species (ROS) production; and porphyrin/heme transport, among several other putative functions [1, 19-22]. Most of these studies were performed in steroidogenic primary cultures or cell lines, with limited studies in primary glial cells. Further, the first effort to generate global TSPO knockout (KO) mice described that the TSPO-KO mice were unable to survive and that global Tspo deletion was embryonic lethal [21]. However, new evidence has emerged that has questioned the dogma that global deletion of Tspo is embryonic lethal and that TSPO plays an essential role in steroidogenesis or regulates the mPTP. Since 2014, studies have shown that global TSPO-KO mice are viable and that TSPO does not appear to be required for steroidogenesis [23-25] or to participate in the regulation of the mPTP [26]. Structural biology studies also show that oligomerization of TSPO is unlikely to form a pore for cholesterol transport, as previously proposed [27]. These contradictory findings have generated significant controversy and confusion in the scientific literature related to the cellular function(s) of TSPO. Therefore, elucidating the functional significance of TSPO upregulation in glial cells under conditions of diverse neuropathology is important in order to advance the understanding of TSPO and glial cell biology.

Microglia are the resident immune cells of the brain with an ability to sense and respond to cellular signals resulting from disruption of brain homeostasis [28, 29]. Microglia have a specific morphological and functional response when they are activated, changing from a ramified morphology to one with thickened and shortened processes [28, 29]. Additionally, microglia significantly increase TSPO expression when they are activated with a time course that is dependent on the type and degree of injury $[1,3]$. Although TSPO appears to play a role in the neuroinflammatory response, there is a lack of knowledge concerning the precise molecular and cellular function(s) of TSPO in the microglial response to brain injury.

Our laboratory has previously shown that microglia exposed to physiologically relevant concentrations $(1-100 \mathrm{nM})$ of TSPO-specific ligands (i.e., (R)-PK11195 and Ro5-4864) increased ROS production that was abrogated by different types of NADPH oxidase (NOX2) inhibitors [30]. These experiments provided the initial evidence of a putative association between TSPO and NOX2 in microglia. NOX2 is a major source of ROS production in the central nervous system, and similar to TSPO, it is highly enriched in microglia [31, 32]. NOX2 is a multi-subunit enzyme composed of the cytosolic subunits $\mathrm{p} 40^{\text {phox }}, \mathrm{p} 47^{\text {phox }}, \mathrm{p} 67^{\text {phox }}$, the small G protein Rac1, and the integral membrane subunits $\mathrm{p} 22^{\text {phox }}$ and $g p 91^{\text {phox }}$ (gp91 ${ }^{\text {phox }}$ is also called NOX2). The principal membrane subunit $\mathrm{gp} 91^{\text {phox }}$ is processed and matured in the endoplasmic reticulum (ER) via the incorporation of two heme molecules into its glycosylated precursor gp 65 , followed by dimerization with $\mathrm{p} 22^{\text {phox }}$ to form the heterodimer, flavocytochrome $b_{558}$ $\left(\mathrm{Cytb}_{558}\right)$, and further glycosylation in the Golgi [33-36]. The $\mathrm{Cytb}_{558}$ heterodimer then traffics to the plasma membrane and endosomal compartments. In the plasma membrane, $\mathrm{Cytb}_{558}$ contributes the catalytic core of the membrane-embedded NOX2 enzyme [33-36]. Importantly, the incorporation of heme into gp9 $1^{\text {phox }}$ in the ER is essential for $\mathrm{Cytb}_{558}$ formation, since in the absence of heme, gp $91^{\text {phox }}$ and $\mathrm{p} 22^{\text {phox }}$ do not form a dimer (i.e., $\left(\mathrm{Cytb}_{558}\right.$ ) and are degraded by the proteasome [33-36].

In phagocytes, activation of NOX2 occurs when a stimulus promotes the phosphorylation of the cytosolic subunit $\mathrm{p} 47^{\text {phox }}$. The cytosolic subunits subsequently translocate to the membrane where they assemble with $\mathrm{Cytb}_{558}$ to form a membrane-bound enzymatic complex to generate superoxide by the transfer of two electrons from NADPH to molecular oxygen [37]. Studies have shown that cholesterol is also needed for the NOX2 cytosolic subunits to translocate to the plasma membrane or lipid rafts in order to form an active NOX2 complex [38, 39].

In this study, we provide new experimental evidence of an association between TSPO and the NOX2 subunits gp9 $91^{\text {phox }}$ and $\mathrm{p} 22^{\mathrm{phox}}$ in microglia. We provide a working model suggesting that this interaction may be associated with the TSPOmediated transfer of heme from mitochondria to gp $91^{\text {phox }}$ in the ER. Thus, TSPO may regulate NOX2 levels, ROS production, and redox homeostasis in microglia.

\section{Materials and Methods}

Culture of Cell Lines Human female HEK293T (RRID: CVCL_0063) and mouse female macrophage J774.A1 (RRID: CVCL_0358) (provided in 2011 by Dr. Martin 
Pomper's laboratory, Johns Hopkins Medical Institution, Baltimore, MD) cell lines were maintained in DMEM and RPMI media (Life Technologies, Carslbad, CA) respectively, with $10 \%$ fetal bovine serum (FBS; Hyclone, GE Healthcare Life Sciences, Marlborough, MA) and 1\% (vol/vol) penicillinstreptomycin. These cell lines were used to validate the quality of the antibodies used in the microglia experiments and not for studies on the TSPO-NOX2 subunit interaction.

Primary Microglia Cell Culture All studies examining the TSPO-NOX2 subunit association were performed in murine primary microglia cultures. Primary murine mixed glial cell cultures were prepared using a modified version of the glial culture technique as previously described using post-natal day (PN) 1-3 C57/B16 mouse pups [40, 41]. Breeder animals were obtained from Envigo (Indianapolis, IN) and bred in house (1 male, 1 female) to generate litters until female breeders were 9 months of age. For each dissection, 10-18 brains (dependent on litter number and size) were extracted and meninges were removed from PN1-3 C576/B16 mouse pups. Brain tissue was dissociated with $0.25 \%$ trypsin (Thermo Fisher Scientific, Waltham, MA), in a $37{ }^{\circ} \mathrm{C}$ water bath for $30 \mathrm{~min}$, and tissue was shaken by hand every $5 \mathrm{~min}$. Trypsinization was stopped with equal volume of DMEM F-12 media (Life Technologies, Carslbad, CA) supplemented with 10\% FBS (Hyclone, GE Healthcare Life Sciences, Marlborough, MA) and 1\% (vol/ vol) penicillin-streptomycin (Life Technologies, Carlsbad, CA). Tissue was triturated using various sized pipettes to create a single cell suspension of brain tissue and ultimately filtered using a $70-\mu \mathrm{m}$ mesh filter (BD, Franklin Lakes, NJ). Single cell suspension was combined with fresh DMEM F12 media such that cells were seeded with 1 mouse brain across 2 T75 flasks (Corning, Corning, NY) with each flask containing a final volume of $10 \mathrm{~mL}$. Cultures were maintained in a humidified incubator at $37{ }^{\circ} \mathrm{C}$ with $95 \%$ air $/ 5 \% \mathrm{CO}_{2}$. Media was changed at day 4-5 post dissection. After $12-$ 14 days in culture, microglia were separated from the glial cultures by shaking the flasks for $3 \mathrm{~h}$ at 120 r.p.m. in a temperature-controlled shaking incubator and collecting the floating cells in the media. After centrifugation for $10 \mathrm{~min}$ at $400 \times g$, cell viability was determined by trypan blue exclusion, and cells were plated at various densities according to the experiment being performed ( 12 well plate: $1 \times 10^{5}$ cells per well on poly-L-lysine coated coverslips (Fisher Scientific, Hampton, NH. $60-\mathrm{cm}$ plate: $5 \times 10^{5}$ cells per plate). Approximately $94 \%$ or greater of the adherent cells were positive for the microglia-specific marker Mac-1 as determined by immunostaining. Cells rested overnight $(16-20 \mathrm{~h})$ before any dosing or assays were performed. Animals used for these studies were in accordance with relevant guidelines and regulations, and all studies were reviewed and approved by Columbia University and Florida International University Animal Care \& Use Committees.
Antibody Validation Using siRNA Transfection HEK293T cells were transfected with siRNAs using Lipofectamine 2000 (Life Technologies, Carlsbad, CA) and harvested at 48-h post-transfection. The Silencer Select Validated siRNA (ID: s224728, Applied Biosystems-Thermo Fisher Scientific, Waltham, MA) was used to knockdown TSPO in HEK293 T cells, with the Silencer Select Negative Control \#1 siRNA (Applied Biosystems-Thermo Fisher Scientific, Waltham, MA) as scramble siRNA control.

Antibody Validation Via Gene Silencing by Spinoculation Using shRNA Lentiviral Particles Due to the sensitive nature of primary microglia to be activated by manipulation and their inability to be cultured for long periods of time, validation of TSPO, gp9 $1^{\text {phox }}$, and $\mathrm{p} 22^{\text {phox }}$ antibodies was performed using shRNA transduction in J774.A1 murine macrophage cell line. The J774.A1 macrophages cell line is of the same species as the primary microglia cultures (mouse) and a related cell type as microglia are considered macrophages of the central nervous system. All shRNAs and empty vectors used in this study were from Sigma-Aldrich MISSION (St. Louis, MO). Clones tested included TSPO (Tspo): TRCN00000102106 (\#102106); TRCN00000102107 (\#102107); TRCN00000102109 (\#102109). gp91 ${ }^{\text {phox }}(C y b b)$ : TRCN00000435339 (\#435339); TRCN00000422819 (\#422819); TRCN00000240564 (\#240564). p22 ${ }^{\text {phox }}(C y b a)$ : TRCN00000240562 (\#240562); TRCN00000240565 (\#240565); TRCN00000011889 (\#011889). Clones \#102106 (TSPO), \#435339 (gp91 ${ }^{\text {phox }}$ ), and \#240565 (p22 ${ }^{\text {phox }}$ ). A suspension of 100,000 cells $/ \mathrm{ml}$ was treated with $8 \mu \mathrm{g} / \mathrm{ml}$ of hexadimethrine bromide $(107,689$, Sigma-Aldrich, St. Louis, MO) and lentiviral particles at a multiplicity of infection (MOI) of 15 . Cells were centrifuged at $800 \times \mathrm{g}$ for $30 \mathrm{~min}$ at room temperature and were resuspended and plated at a density of 20,000 cells/well. After $48 \mathrm{~h}$, cells were treated with $1 \mu \mathrm{g} / \mathrm{ml}$ puromycin (A11138, Life Technologies, Carlsbad, CA) for 4.5 days to select for cells which had been transduced. After puromycin selection, cells were grown in fresh media for 7 days before harvesting for Western blot.

LPS Treatment Bacterial lipopolysaccharide (LPS, SigmaAldrich, St. Louis, MO) was dissolved in phenol red free DMEM F-12 media (Life Technologies, Carlsbad, CA) to create a stock solution of $1 \mathrm{mg} / \mathrm{mL}$. A solution of $100 \mathrm{ng} /$ $\mathrm{mL}$ of LPS was made fresh for each experimental exposure. J774.A1 cells were exposed to $1 \mu \mathrm{g} / \mathrm{ml}$ for 3 and $24 \mathrm{~h}$. Microglia were exposed to $100 \mathrm{ng} / \mathrm{mL}$ of LPS for time of exposure indicated.

Western Blotting Standard Western blotting as seen in Supplemental Figure S1 was performed using the anti-TSPO antibody (Epitomics/Abcam, Cambridge, UK, 3623-1, 1:1000; RRID:AB_10897701) and anti-ß-actin antibody 
(Santa Cruz, Santa Cruz, CA, sc-1616, RRID:AB_630836, $1: 2500)$ as the primary antibodies. The Odyssey Infrared Imaging system was used for fluorescence immunoblotting with IRDye dye-labeled secondary antibodies (LI-COR Biosciences, Lincoln, NE, 1:5000) For Western blotting methods used in immunoprecipitation experiments, see below.

$\left[{ }^{3} \mathrm{H}\right]-\mathrm{R}-\mathrm{PK} 11195$ Binding Assay Binding assays were performed using macrophage J774.A1 cells harvested $3 \mathrm{~h}$ or $24 \mathrm{~h}$ after treatment with vehicle or LPS. On the day of the assay, cell pellets were thawed and sonicated in $50 \mathrm{mM}$ Tris$\mathrm{HCl}$ assay buffer ( $\mathrm{pH}$ 7.4) and distributed into assay tubes to provide approximately $25-150-\mu \mathrm{g}$ protein/tube. Protein concentration was determined by Bradford protein assay using bovine serum albumin as a standard. The final assay volume was $0.5 \mathrm{ml}$ and all tubes were kept on ice during preparation. Cell suspensions were incubated in triplicate and binding was determined using $\left[{ }^{3} \mathrm{H}\right]-\mathrm{R}-\mathrm{PK} 11195$ (specific activity $84.8 \mathrm{Ci} /$ mmol, Perkin Elmer, Waltham, MA) at a $2-2.5 \mathrm{nM}$ concentration. Nonspecific binding was measured in the presence of $50 \mu \mathrm{M}$ non-radioactive PK11195 (Sigma-Aldrich, St. Louis, $\mathrm{MO})$. Assay tubes were incubated for $1 \mathrm{~h}$ at $4{ }^{\circ} \mathrm{C}$. The reaction was terminated by filtration through Whatman GF/B filter paper (Brandel, Gaithersburg, MD) with a Brandel harvester system (Brandel, Gaithersburg, MD). Filters were washed three times with $4 \mathrm{ml}$ of ice-cold assay buffer. Radioactivity retained in the filters was measured by liquid scintillation spectrometry using $10 \mathrm{ml}$ of complete counting cocktail (Econo-Safe; Research Products International).

Transgenic Mice The animal procedures described in this study were approved by Florida International University Institution Animal Care \& Use Committee. Six mice (4 female and 2 male) heterozygous for TSPO were obtained from Helmholtz Zentrum Munich German Mouse Clinic as part of the International Mouse Phenotyping Consortium (IMPC) and INFRAFRONTIER/European Mouse Mutant Archive (EMMA). TSPO tm1b mice (RRID:IMSR_EM:09345) were produced on a C57BL/6NTac background and mice were produced by treating 2-cell embryos with Cre enzyme as described previously [42]. Tm1b allele embryos have a reporter-tagged deletion allele (post-Cre). Critical exons, in this case exons 2 and 3 of Tspo, are deleted by creating a frame shift using the Cre method. Genotypes of animals were validated through endpoint PCR. When TSPO heterozygous mice arrived in the USA, animals were quarantined for 2 weeks and then allowed to sexually mature until all animals were at least 8 weeks of age. To generate TSPO wildtype, heterozygous, and knockout animals, TSPO heterozygous animals were bred in harem ( 2 females, 1 male), and used as breeders until the female was 8 months of age or the female stopped producing litters after 3 attempts at breeding.
Immunoprecipitation and Western Blots Cells were plated onto $60-\mathrm{mm}$ dishes at a density of 500,000 cells per dish. Cells were harvested in a mild lysis buffer containing $0.2 \mathrm{mM}$ sodium orthovanadate, $5 \mathrm{mM}$ sodium fluoride, $0.5 \% \mathrm{NP}-40,2.5 \mathrm{mM}$ ethylenediaminetetraacetic acid (EDTA), $150 \mathrm{mM}$ potassium chloride, and $10 \mathrm{mM}$ Tris, pH 7.4 [43]. Multiple microglia extractions were combined in order to achieve a $415 \mu \mathrm{g}$ protein concentration per treatment condition for each immunoprecipitation (IP) experiment. Cells were harvested for whole cell protein levels using the method of [44]. Protein concentration was determined using the Lowry assay.

A sample of the initial cell lysate was retained for analysis of total protein and Western blot and it is referred to as the "input fraction." For each immunoprecipitation experiment, cell lysates were pre-cleared by incubating the lysate with $50 \mu \mathrm{L}$ of IgG coated beads (Protein G Dynabeads) (Life Technologies, 10-007-D, Carlsbad, CA) for $2 \mathrm{~h}$ to eliminate any nonspecific binding to beads. Samples were then incubated with the anti-TSPO antibody (Abcam, Cambridge, MA, ab109497, RRID: AB_10862345, 1:10 $(\mu \mathrm{g} / \mu \mathrm{L}))$ overnight at $4{ }^{\circ} \mathrm{C}$. Next, lysates were incubated for $2 \mathrm{~h}$ with $200 \mu \mathrm{L}$ of Protein $G$ Dynabeads to allow the $F_{c}$ region of the antibody to bind to the IgG coated beads. All IP-related incubations were performed at $4{ }^{\circ} \mathrm{C}$. An IP sample without any TSPO antibody was run in parallel as a negative control for the IP (no primary pulldown) to ensure specificity of the bands detected. Proteins were separated on 4-15\% TGX Precast Gels (Biorad, Hercules, CA) and transferred to polyvinylidene difluoride (PVDF) membranes. For non-IP samples (i.e., the input fraction), $25 \mu \mathrm{g}$ of protein was loaded per condition per lane. Immobilon-FL PVDF Western blot membranes (EMD Millipore, Burlington, MA, IPFL00010) were incubated with corresponding primary antibodies: goat anti-TSPO (Abcam, Cambridge, MA, ab118913, RRID:AB_10898989 1:1000); rabbit anti-TSPO (Abcam, Cambridge, MA, 109497, RRID:AB_10862345 1:1000); mouse anti-gp91 ${ }^{\text {phox }}(\mathrm{BD}$ Biosciences, San Jose, CA, 611415, RRID:AB_398937, 1:200); mouse anti-p22 ${ }^{\text {phox }}$ (Santa Cruz Biotechnology, Dallas, TX, sc-130,551, RRID:AB_2245805, 1:100); rabbit anti-mouse VDAC (Abcam, Cambridge, MA, ab15895, RRID:AB_2214787, 1:500). Quick Western Kit IRDye 680RD (LI-COR Biosciences, Lincoln, NE, 926-69100) was used as it does not bind to denatured mouse or rabbit monoclonal antibodies. Standard Western blot LI-COR (Lincoln, NE) secondary antibodies (IRDye $800 \mathrm{CW}$ Donkey anti-Mouse and IRDye 680LT donkey anti-rabbit, 1:10,000) were also used to confirm the specificity of Quick Western Kit IRDye 680RD (LI-COR Biosciences, Lincoln, NE, 926-68100).

Gene Expression and RT-PCR Gene expression for Tspo, $C y b b$, $C y b a, V D A C 1$, and GAPDH was performed. RNA was isolated 
from primary mouse microglial cells treated with vehicle or $100 \mathrm{ng} / \mathrm{mL}$ LPS for $18 \mathrm{~h}$ by using RNAqueous Micro Kit (AM1931, Invitrogen, Carlsbad, CA). RNA content was measured using NanoDrop spectrophotometer (Thermo Fisher Scientific, Waltham, MA). Reverse transcription of RNA was performed with High-Capacity RNA-to-cDNA kit (Applied Biosystems, Thermo Fisher Scientific, Waltham, MA). qRTPCR was performed using $1 \mu \mathrm{l}$ of cDNA diluted to $20 \mathrm{ng} / \mu \mathrm{l}$, TaqMan multiplex master mix (Applied Biosystems, Thermo Fisher Scientific, Waltham, MA) and TaqMan mouse primers (Thermo Fisher Scientific, Waltham, MA) in a final reaction of volume of $10 \mu \mathrm{l}$. Primers used included Tspo (Mm00437828_m1-FAM-MGB); Cybb (Mm01287743_m1FAM-MGB); Cyba (Mm00514478_m1-FAM-MGB); Vdac1 (Mm00834272 m1-FAM-MGB); and Gapdh (Mm999999915_g1-VIC-MGB). The results were evaluated using QuantStudio Real-Time PCR Software v1.3 (Thermo Fisher Scientific, Waltham, MA). Amplification specificity was confirmed by melting curve analysis, and the quantification was carried out using the $\Delta \Delta \mathrm{Ct}$ method [45]. All samples were normalized to Gapdh. Data from six independent experiments were run on the same plate for each gene. All individual samples were run in triplicate.

Immunocytochemistry Microglia $\left(1 \times 10^{5}\right)$ were plated on poly-1-lysine glass coverslips (Fisher Scientific, Pittsburgh, PA, 08-774-383) in 12-well plates. Cells were treated for $18 \mathrm{~h}$ with vehicle (media) or $100 \mathrm{ng} / \mathrm{mL}$ LPS in media supplemented with $2 \%$ FBS ( $2 \mathrm{~mL}$ solution per well; Hyclone, GE Healthcare Life Sciences, Marlborough, MA). Immunocytochemistry was performed via conventional techniques. That is, cells were fixed with $4 \%$ paraformaldehyde (PFA) and permeabilized with $0.2 \%$ Triton X-100. Blocking was performed with $10 \%$ normal donkey serum (Jackson Laboratories, Bar Harbor, ME) for $3 \mathrm{~h}$ before being incubated with primary antibodies. Goat anti-TSPO (Abcam, Cambridge, MA, ab118913, RRID:AB_10898989, 1:500); mouse anti-gp91 ${ }^{\text {phox }}$ (BD Biosciences, San Jose, CA, 611415, RRID:AB 398937, 1:100); mouse anti-p22 $2^{\text {phox }}$ (Santa Cruz Biotechnology, Dallas, TX, sc-130,551, RRID:AB_2245805, 1:100); rabbit anti-VDAC (Abcam, Cambridge, MA, ab15895, RRID:AB_2214787, 1:500) were used. After washing, cells were incubated with appropriate Alexa Fluor secondary antibodies for $1 \mathrm{~h}$ (Life Technologies, Carlsbad, CA; AF 488, 594, and 647, 1:500). Coverslips were mounted with Prolong with DAPI (Life Technologies, Carlsbad, CA) to counterstain for cell nuclei.

Immunohistochemistry Free-floating brain sections from PFA-perfused mice were sectioned at $40 \mu \mathrm{m}$ using a freezing microtome (Leica Microsystems Inc., Bannockburn, IL). Sections were stored at $-20{ }^{\circ} \mathrm{C}$ in cryoprotectant consisting of $50 \%$ glycerol in $0.05 \mathrm{M}$ phosphate buffer. For immunofluorescence triple labeling of Mac-1, TSPO, and gp91 ${ }^{\text {phox }}$, free-floating brain sections were washed with $1 \mathrm{X}$ Tris-buffered saline (TBS) for $60 \mathrm{~min}$, with fresh TBS every $10 \mathrm{~min}$. Sections were then blocked with 5\% normal donkey serum (Jackson Laboratories, Bar Harbor, ME) containing $0.2 \%$ Triton $\mathrm{X}-100$ for $1 \mathrm{~h}$ followed by primary antibody incubation: rat-anti-Mac-1 (BD Biosciences, San Jose, CA, 553308, 1:250, RRID:AB 394772), rabbit anti-TSPO (Abcam, Cambridge, MA; ab109497, RRID:AB_10862345, 1:500), and goat anti-gp91 ${ }^{\text {phox }}$ (Santa Cruz Biotechnology, Dallas, TX, (sc-5827), RRID:AB_647636, 1:150) at $4{ }^{\circ} \mathrm{C}$ overnight in $2 \mathrm{~mL}$ of solution. After washing, sections were incubated with appropriate Alexa Fluor secondary antibodies (Life Technologies, Carlsbad, CA; 1:500) for $1 \mathrm{~h}$ and underwent another series of washes post-secondary antibody incubation. Sections were mounted on slides and coverslipped with Prolong Gold Antifade Mountant (Life Technologies, Carlsbad, CA) to preserve signal intensity and brightness.

Immunofluorescence Imaging and Analysis For In Vitro Experiments Immunofluorescence-labeled cells were imaged at $\times 60$ magnification with a $1.6 \times$ zoom using a laser scanning confocal microscope (Fluoview FV10i, Olympus, Center Valley, PA), utilizing the FV10 image software. All coverslips stained under the same conditions were imaged using the same scanning parameters on the same day. Images were scanned at a resolution of $512 \times 512$ pixels. Five to six confocal stacks were obtained for each experimental condition with at least 25 cells counted per condition. In order for a cell to be counted, the entire cell needed to be within the frame of the image. Confocal stacks were projected as single images using the maximum fluorescence FV10 software. Maximum intensity projection images for each channel were converted to a gray scale image using Photoshop.

All images were analyzed using Metamorph Offline (Molecular Devices, Downington, PA). Threshold values were determined by eye by a single experimenter for all experiments, and threshold values were kept consistent across both vehicle and LPS conditions within an experiment. Threshold values and colocalization results were crosschecked by having a second experimenter perform colocalization analysis on a subset of cells and compare results of the 2 experimenters; results of the 2 experimenters varied by $<2 \%$. Regions of interest (ROIs) were manually created around each cell in the VDAC channel. ROIs were drawn to be the shape of the cell, with about a $10 \%$ buffer of space between the ROI outline and the signal from the cell. ROIs were transferred to the TSPO channel and the NOX2 subunit channel using the Metamorph Transfer Function such that each ROI outlined each cell, in each channel. ROIs were cross-checked in the TSPO and NOX2 subunit channels to ensure all fluorescent signal due to cell expression was captured within the ROI for each channel. 
For colocalization analyses, gray scale images of each wavelength (each protein) were used to examine the area of colocalized pixels of both wavelengths to calculate the percent colocalization of their signals using the Metamorph Application "Measure Colocalization." Percent colocalization was calculated as previously described [46]. Briefly, colocalization of protein A with protein B equals area (A with $\mathrm{B})$ divided by total area (A) where $\mathrm{A}$ and $\mathrm{B}$ are individual wavelengths for the same image. To assess colocalization of 3 proteins (proteins A, B, and C), a new image (AB') was generated that consisted of pixels when $\mathrm{A}$ and $\mathrm{B}$ colocalized. The colocalization of proteins $(\mathrm{A}+\mathrm{B})$ with $\mathrm{C}$ was then quantified using images $\mathrm{AB}^{\prime}$ and $\mathrm{C}$.

\section{Immunofluorescence Imaging and Analysis For Ex Vivo} Experiments Four to six images were acquired in the ventral posteromedial thalamic nuclei from horizontal brain sections in age matched wildtype and Sandhoff disease animals with four male animals per group. This area of the thalamus was chosen based off of prior studies by Loth et al. [47] that have shown TSPO upregulation specific to Sandhoff disease in this brain region. Imaging was done at $\times 60$ magnification with a $1.6 \times$ zoom using a laser scanning confocal microscope (Fluoview FV10i, Olympus, Center Valley, PA), utilizing the FV10 image software. Colocalization was calculated as describe above for proteins $\mathrm{A}, \mathrm{B}$, and $\mathrm{C}$ to assess when TSPO colocalizes with gp9 $1^{\text {phox }}$, what percentage of that colocalizes with the microglia marker Mac-1. Colocalization analysis was performed on the entire image (no ROIs were drawn) as expression of all markers was consistent across the field of view in the image.

Duolink Proximity Ligation Assay Briefly, samples were incubated with primary antibodies to bind to the two proteins of interest. Secondary antibodies conjugated with positive and negative oligonucleotides (proximity ligation assay (PLA) probes) were then incubated with the cells. Next, ligase and two additional oligonucleotides were introduced, and these oligonucleotides hybridize to the PLA probes, and if in close enough proximity $(\sim 30-40 \mathrm{~nm})$, form a closed circle. In the DNA circle, one of the antibody conjugated DNA probes serves as a primer for rolling circle amplification (RCA) and a repeated sequence (concatemeric) product was generated when DNA polymerase and nucleotides were added. Fluorescently labeled oligonucleotides proceed to bind to the RCA product and allowed visualization of the protein-protein interaction as single dots via fluorescence microscopy. PLA experiments were performed according to the manufacturer's instructions with minor modifications (Sigma-Aldrich, St. Louis, MO; Duolink In Situ Detection Reagents Red, DUO92008) including increase volume of solution for each coverslip. After vehicle or LPS treatment, cells were fixed with $4 \%$ PFA. Cells were permeabilized with $0.2 \%$ Triton X-100 for 25 min and blocked with 10\% normal donkey serum before being incubated for corresponding primary antibodies for $72 \mathrm{~h}$ at $4{ }^{\circ} \mathrm{C}$ : goat anti-TSPO (Abcam, Cambridge, MA, ab118913, RRID:AB 10898989, 1:500); mouse anti-gp91 ${ }^{\text {phox }}$ (BD Biosciences, San Jose, CA, 611415, RRID:AB 398937, 1:200); mouse anti-p22 $2^{\text {phox }}$ (Santa Cruz Biotechnology, Dallas, TX, sc-130,551, RRID:AB 2245805, 1:100); rabbit anti-mouse VDAC (Abcam, Cambridge, MA, ab15895, RRID:AB_10862345, 1:500) with $100 \mu \mathrm{L}$ of solution per coverslip. After washing, cells underwent exposure to PLA Probes (Goat PLUS RRID:AB_10971336, and Mouse MINUS RRID:AB 2713942; or Goat PLUS RRID:AB_10971336, and Rabbit MINUS, RRID:AB_2810942); ligation solution, and amplification solution as per manufacturer's instructions.

TSPO Immuno-Gold Electron Microscopy in Primary Microglia Microglia were plated at a density of $5 \times 10^{5}$ in a 6 -cm plate. Cells were treated with either vehicle or LPS $(100 \mathrm{ng} / \mathrm{mL}$; $3 \mathrm{ml}$ of solution per plate) for $18 \mathrm{~h}$. Following exposure, cell culture media was removed from the cells and replaced with a $4 \%$ PFA and $0.1 \%$ glutaraldehyde fixative. The fixative was left on the cells for $1 \mathrm{~min}$ and replaced with two successive changes of new media. Cells were left to fix for a total of $30 \mathrm{~min}$. After fixation, a $1 \%$ sodium borohydride solution for antigen retrieval was used to rinse the cells for $20 \mathrm{~min}$. After antigen retrieval, cells were cryoprotected using incubations of increasing concentrations of an $8 \%$ glycerol and $20 \%$ sucrose solution dissolved in $0.1 \mathrm{M}$ phosphate-buffered saline (PBS) before placement into the $-80^{\circ} \mathrm{C}$ freezer. The freezing served to rupture the cell membranes less harshly than traditional detergents. Cryoprotectant was removed from the cells, using successively increasing concentrations of PBS in PBScryoprotectant mixture. The cryoprotection and freezing process was repeated twice to ensure antibody penetration into the fixed cells. Nonspecific binding sites were then blocked in the cells using a $30-$ min incubation in a 5\% BSA-PBS blocking buffer. After, cells were incubated in primary antibody for $24 \mathrm{~h}$ at room temperature followed by $48 \mathrm{~h}$ at $4{ }^{\circ} \mathrm{C}$ using a 1:200 dilution of monoclonal rabbit anti-TSPO antibody (Abcam, Cambridge, MA) in the 5\% BSA blocking buffer. After incubation in the primary antibody, cells were rinsed four times in PBS and were left to incubate in a 1:200 diluted $0.5-\mathrm{nm}$ gold nanoprobe secondary antibody in 5\% BSA blocking buffer, for $24 \mathrm{~h}$ at room temperature followed by $48 \mathrm{~h}$ at $4{ }^{\circ} \mathrm{C}$. After secondary antibody incubation, cells were rinsed four times in PBS and two times in a $245 \mathrm{mM}$ sodium acetate buffer. Gold nanoprobes were then enhanced using a silver HQ kit (Nanoprobes, Yaphank, NY). The enhancement reagent was prepared using the kit directives and applied to the cells for a total of 4 min for silver enhancement. The silver enhancement reaction was halted using a $0.1 \mathrm{M}$ sodium thiosulfate rinse for $3 \mathrm{~min}$, followed by three quick sequential rinses with sodium acetate buffer and a rinse in 0.1 M PBS. Silver enhancement procedures were carried out 
in the dark, as light exposure could interfere with the reaction and result in the formation of insoluble precipitates. Following the completion of the steps for immunolabeling, cells were postfixed using a $2 \%$ glutaraldehyde solution for $10 \mathrm{~min}$, rinsed in PBS, and incubated in $0.5 \%$ osmium tetroxide in PBS for lipid fixation. Cells were then dehydrated using stepwise increasing concentrations of ethanol in an ethanol-water dilution series. Once the cells reached incubation in $100 \%$ ethanol, they were gently scraped from the Petri dish and pipetted into a microcentrifuge tube containing propylene oxide. Cells were centrifuged at $1500 \mathrm{rpm}$ in a microcentrifuge to keep the cells at the bottom of the tube. All traces of ethanol were removed from the cells using propylene oxide. Cells were infiltrated with resin using increasing concentrations of Spurr resin in a Spurr Resin-propylene oxide mixture (25\%, $50 \%, 75 \%, 100 \%, 100 \%)$. Scraping at the $100 \%$ ethanol step in this multistep protocol helped to minimize cell loss. Moreover, incubations in osmium tetroxide, uranyl acetate, and silver increased the density of the cells, which facilitated fewer, low-speed centrifugation. This approach aided in the preservation of ultrastructure. After infiltration, $500 \mu \mathrm{L}$ of fresh resin was used to replace old resin in the microcentrifuge tube. The resin polymerized over $24 \mathrm{~h}$ at $60^{\circ} \mathrm{C}$. After polymerization, the resin block was removed from the microcentrifuge tube using a razor blade. Sixty-nanometer ultrathin sections were cut using a Diatome diamond knife (EMS Diasum, Hatfield, PA) on Leica (Buffalo Grove, IL) Ultracut UCT ultramicrotome. Two hundred mesh nickel grids were used to support the sections. Sections were stained using an aqueous $4 \%$ uranyl acetate solution for $30 \mathrm{~min}$ at room temperature in the dark. Sections were rinsed in water and stained in a lead citrate solution for $6 \mathrm{~min}$. Sections were rinsed in water and left to dry before examination in a FEI Tecnai Spirit Transmission Electron Microscope operated at $60 \mathrm{kV}$. Images were obtained using an AMT camera and image analysis software.

Flow Cytometric Assays To measure cellular ROS and surface TSPO expression levels, the CellROX® green flow cytometry assay kit was used (Thermo Fisher, Waltham, MA; C10492). Immediately after harvesting from a mixed glia culture, primary microglia cells were treated with and without $5000 \mu \mathrm{M}$ $\mathrm{N}$-acetyl cysteine (NAC), a ROS scavenger, for $1 \mathrm{~h}$ at $37^{\circ} \mathrm{C}$, followed by $400 \mu \mathrm{M}$ of tert-butyl hydroperoxide (TBHP), an ROS inducer, for $45 \mathrm{~min}$ at $37^{\circ} \mathrm{C}$. Cells were then stained with $500 \mathrm{nM}$ CellROX® Green Reagent for $45 \mathrm{~min}$. Cells were also stained for surface TSPO expression without cellular permeabilization by adding TSPO-conjugated PE antibody (Abcam, Cambridge, MA; ab208836, 1:100) followed by fixation with 3\% PFA. The CellROX® green flow cytometry kit was used in conjunction with SYTOX® Red Dead Cell Stain to differentiate live cells from dead cells. Cells were then analyzed by Becton Dickinson FACSMelody. Quantification of CellROX ${ }^{\circledR}$ green ROS probe signal was determined by the mean fluorescence intensity (MFI) using FlowJo software.

Bioinformatic Model and Alignment of TSPO Using established software sources, we aligned and modeled human TSPO (hTSPO) from the Uniprot sequence P30536-1 (accessed on May 30, 2020) to mouse TSPO (mTSPO; PDB: 2mgy.1) bound to PK11195 and Rhodobacter sphaeroides (rTSPO; PDB: 4uc1.1.B) bound to protoporphyrin IX (PPIX). Protein sequences for these structures were obtained through sequences deposited in the SWISSMODEL workspace [48] accompanying the deposited structures listed above. The sequences were aligned to identify conserved sequences using the multiple alignment viewer, MView, produced by the European Bioinformatics Institute (EMBL-EBI) [49]. To model the hTSPO to the mTSPO PDB 2mgy. 1 structure, we used the SWISS-MODEL software [48] and we compared the structure to other TSPO structures from mTSPO (PDB: 2n02.1) and rTSPO (4uc1.1, 4uc1.2, and 4uc3.1) to ensure the hTSPO model was in agreement with the major topological features of existing crystal structures. The hTSPO model was provided with a coloring scheme that permitted the distinct viewing of helices and other secondary structure elements, and surface topology predictions were used to interrogate the presence of hydrophobicity and aromaticity within the model. Next, both the primary sequence and structural model of hTSPO were entered in to the HemeBind software [50] to identify potential amino acids capable of interacting with heme. The residues were then examined and visualized on the hTSPO model using the SWISS-MODEL software package. Figure images were prepared by exporting renderings from the SWISS-MODEL software into Photoshop, where only cropping of white edges and labeling were performed. Otherwise, the image was unaltered after export from SWISS-MODEL.

Statistical Analysis Values are expressed as mean \pm standard error of the mean (SEM). Student's paired $t$ tests were performed for Western Blot analyses and colocalization analyses. A two-way analysis of variance was performed for colocalization analysis between wildtype and Sandhoff mice at 4 different ages. For all tests, significance level was set at $p<0.05$. For percent vehicle values, statistics were performed on log-transformed values.

\section{Results}

Co-immunoprecipitation of TSPO with gp9 ${ }^{\text {phox }}$, p22 ${ }^{\text {phox }}$, and VDAC in Microglia To explore the putative association between TSPO and the NOX2 principal subunits gp $91^{\text {phox }}$ and $\mathrm{p} 22^{\text {phox }}$, we performed TSPO immunoprecipitation experiments of primary mouse microglia using antibodies independently 
validated in our lab (Supplementary Fig. S1) under both LPSactivated and vehicle conditions. Primary murine microglia cultures were greater than $94 \%$ pure as determined by macrophage integrin 1 (Mac-1 also called CD11b) immunostaining (Supplementary Fig. S2). For these studies, we also used voltage-dependent anion channel (VDAC) as a positive control because TSPO and VDAC have been shown to coimmunoprecipitate and colocalize in mitochondria [51, 52].

Figure 1a shows western blots of TSPO, gp91 ${ }^{\text {phox }}, \mathrm{p} 22^{\text {phox }}$, and VDAC protein levels in the input fraction (whole cell lysate) under vehicle and LPS-activated conditions. Quantification of proteins in the input fraction by Western blot showed that TSPO, gp91 ${ }^{\text {phox }}$, and $\mathrm{p} 22^{\text {phox }}$ protein levels significantly increased following LPS activation ( $100 \mathrm{ng} / \mathrm{mL}$ for $18 \mathrm{~h}$ ) relative to vehicle conditions (Fig. $1 \mathrm{~b}$ and Supplementary Fig. S3 and S4). VDAC protein levels did not change with LPS-induced activation of microglia (Fig. 1b). To confirm the pattern of increased protein expression in LPS-activated microglia, we performed quantitative real-time PCR under the same conditions. Figure 1c shows that the protein changes following LPS exposure are supported by the gene expression results (Fig. 1c). Notably, LPS concentration (100 ng/ml) and duration of exposure $(18 \mathrm{~h})$ used to activate microglia were determined to be noncytotoxic (Supplementary Fig. S2). Supplementary Fig. S3 shows the full blots shown in Fig. 1. The results of the TSPO co-immunoprecipitation studies using a validated TSPO antibody and detection of TSPO, gp91 $1^{\text {phox }}, \mathrm{p} 22^{\text {phox }}$, and VDAC proteins in the TSPO-precipitated fraction is presented in Fig. 1d. Western blot of the TSPO-immunoprecipitated fraction shows that gp91 ${ }^{\text {phox }}, \mathrm{p} 22^{\text {phox }}$, and VDAC are associated with
TSPO, providing the first direct evidence of a TSPO association with gp91 ${ }^{\text {phox }}$ and $\mathrm{p} 22^{\text {phox }}$.

When we compared the level of these proteins in the TSPO-precipitated fraction from LPS- and vehicle-treated microglia, we found that LPS treatment resulted in a significant decrease in the levels of gp $91^{\text {phox }}$ and $\mathrm{p} 22^{\text {phox }}$ protein that coimmunoprecipitated with TSPO, with no change in VDAC protein levels (Fig. 1e). Overall, these findings indicate that gp91 ${ }^{\text {phox }}$ and $\mathrm{p} 22^{\text {phox }}$ are associated with TSPO under normal physiological conditions. However, these interactions appear to be disrupted by microglia activation with LPS since approximately $40 \%$ less gp $91^{\text {phox }}$ and $\mathrm{p} 22^{\text {phox }}$ protein was immunoprecipitated with TSPO in LPS-treated relative to vehicle-treated microglia. We also confirm that VDAC coimmunoprecipitates with TSPO as previously described [51, 52]. Further, the TSPO association with VDAC was not disrupted by LPS treatment (Fig. 1e). Therefore, based on the TSPO immunoprecipitation results it appears that LPS activation of microglia decreases the association of TSPO with gp9 $1^{\text {phox }}$ and $\mathrm{p} 22^{\text {phox }}$ but not with VDAC, indicating a specific effect of LPS activation on the TSPO-NOX2 subunits interaction.

Immunofluorescence Confocal Imaging Shows Colocalization of TSPO with gp91 ${ }^{\text {phox }}, \mathrm{p} 22^{\text {phox }}$, and VDAC in Primary Microglia To further validate the association of TSPO with gp91 ${ }^{\text {phox }}$, p22 $2^{\text {phox }}$, and VDAC that we observed with the TSPO co-immunoprecipitation experiments, we performed immunofluorescence confocal imaging of TSPO, gp91 ${ }^{\text {phox }}$, $\mathrm{p} 22^{\text {phox }}$, and VDAC in vehicle and LPS-treated microglia and
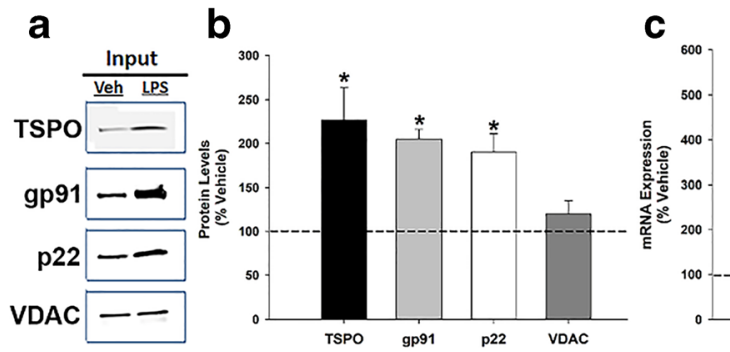

Fig. 1 Co-immunoprecipitation of TSPO, gp9 $1^{\text {phox }}$, p22 $2^{\text {phox }}$, and VDAC and effect of LPS activation on protein-protein interaction in primary microglia. a Western blot of primary microglia whole cell extracts (input) after 18-h exposure to vehicle (media) or $100 \mathrm{ng} / \mathrm{mL}$ LPS. b TSPO, gp $91^{\text {phox }}$, and p $22^{\text {phox }}$ protein levels in whole cell extracts were significantly increased as a result of LPS stimulation, while VDAC protein levels did not change relative to vehicle condition $(n=7-8$ independent experiments; TSPO: $p=0.001$; gp91: $p<0.001$; $222: p<0.001$; VDAC: $p=0.346$ ). $\mathbf{c}$ Quantitative real-time PCR analysis of gene expression levels of the proteins analyzed in A in LPS-activated compared to non-activated microglia ( $n=7$ independent experiments; TSPO: $p<0.001 ; \operatorname{gp} 91: p=0.002 ; \mathrm{p} 22: p<0.001 ;$ VDAC $: p=0.382)$. d Western blot of the immunoprecipitation fraction (IP) with the TSPO antibody from vehicle and LPS-activated microglia confirms that gp91 ${ }^{\text {phox }}, \mathrm{p} 22^{\text {phox }}$, and VDAC proteins co-immunoprecipitates with
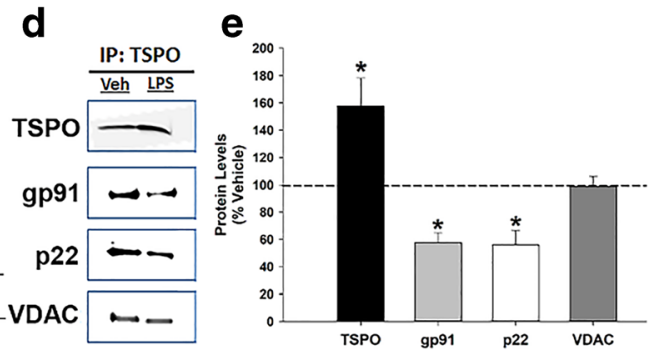

TSPO. e Quantification of protein levels in the TSPO IP fraction from LPS-stimulated microglia shows increased TSPO protein compared to vehicle-treated microglia. On the other hand, the amount of $\mathrm{gp} 91^{\text {phox }}$ and $\mathrm{p} 22^{\text {phox }}$ protein levels pulled-down with TSPO decreased in the LPS condition relative to vehicle-treated cells, suggesting disruption of these protein-protein interactions under LPS-stimulated conditions. No change was found in the degree of TSPO association with VDAC $(n=$ 4-6 independent experiments; TSPO: $p=0.036$; gp91: $p=0.005 ; \mathrm{p} 22$ : $p<0.045$; VDAC: $p=0.743$ ). Data are normalized to vehicle and expressed as mean \pm s.e.m. Student's paired $t$ test was performed; $* p<0.05$ compared to vehicle-treated microglia. Input and IP images for gp91 are from different blots. Input and IP images for p22 and VDAC are from the same blots, but different exposures. For full blots please see Supplementary Fig. S3 
measured colocalization of proteins using a computer-based image analysis program (metamorph — see "Methods" section). For these studies, triple labeling of TSPO-gp91 ${ }^{\text {phox }}$-VDAC or TSPOp2 $2^{\text {phox }}-$ VDAC was performed (see Supplementary Figure S5A$\mathrm{B}$ for representative images of triple labeling). Figure 2a shows TSPO colocalization with gp91 ${ }^{\text {phox }}, \mathrm{p} 22^{\text {phox }}$, and VDAC in primary microglia labeled with Mac-1 at low and high magnifications. The images presented in Fig. 2 were not used for quantification analysis but were used as representative images of the interactions and used Mac-1 to delineate the boundaries of the microglia for presentation purposes. Negative controls in the absence of the primary antibodies for the immunofluorescence confocal studies are provided in Fig. S6A. We also show the absence and presence of TSPO immunostaining in TSPO-KO and wildtype microglia, respectively (Fig. S6B) further confirming the quality of the TSPO antibody. Immunostaining for gp91 ${ }^{\text {phox }}$ remained present in the TSPO-KO microglia (Fig. S6B).

Figure $2 b$ depicts the quantification of the colocalization of TSPO with gp91 $1^{\text {phox }}, \mathrm{p} 22^{\text {phox }}$, and VDAC. We also performed colocalization studies of TSPO with the lysosomal-associated membrane protein-2 (LAMP-2), a lysosomal protein that was not expected to have a high degree of colocalization with TSPO. The results show that the percent colocalization of TSPO with gp91 ${ }^{\text {phox }}, \mathrm{p} 22^{\text {phox }}$, or VDAC was abundant and ranged from approximately $60-80 \%$ (Fig. 2b). On the other hand, TSPO colocalization with LAMP-2 was only approximately $20 \%$ which is significantly less than the NOX2 subunits and VDAC (Fig. 2b; images in Supplementary Fig. S7). These findings indicate that TSPO has a significantly higher degree of colocalization with proteins that have an outer mitochondrial membrane (i.e., VDAC) or ER (gp91 ${ }^{\text {phox }}$, p22 $2^{\text {phox }}$ ) localization than with a lysosomal protein (LAMP-2).

We also compared the colocalization of TSPO with gp91 ${ }^{\text {phox }}$, p22 $2^{\text {phox }}$, and VDAC in vehicle-treated and LPStreated primary microglia. We found an effect of microglia activation with LPS on these putative protein interactions. That is, the percent of gp $91^{\text {phox }}$ or $\mathrm{p} 22^{\text {phox }}$ that colocalized with TSPO decreased significantly from approximately $60 \%$ in vehicle-treated to $40 \%$ in LPS-treated microglia (Fig. 2c). A similar effect was observed with VDAC suggesting that the associations of these proteins with TSPO is partly disrupted when microglia are activated with LPS (Fig. 2c). Moreover, when we analyzed the fraction of the TSPO-gp91 ${ }^{\text {phox }}$ or TSPO-p2 $2^{\text {phox }}$ colocalization that also colocalizes with VDAC, we also observed a decrease with LPS activation (Fig. 2d). The immunofluorescence confocal imaging results are consistent with the co-immunoprecipitation results demonstrating an association of TSPO with gp9 $91^{\text {phox }}, \mathrm{p} 22^{\text {phox }}$, and VDAC and this association is disrupted by LPS activation.

\section{Proximity Ligation Assay Supports a TSPO Interaction with gp $91^{\text {phox }}, \mathrm{p} 22^{\text {phox }}$, and VDAC in Primary Microglia To further}

validate the association of TSPO with gp91 $91^{\text {phox }}, \mathrm{p} 22^{\text {phox }}$, and VDAC in primary microglia, we used a proximity ligation assay (PLA) approach. PLA is a powerful method that can detect protein-protein interaction(s) in the native state of cells with high specificity and sensitivity when proteins are in close proximity (30-40 nm apart or less) [53, 54]. Figure 3a-c depicts confocal-phase contrast images of independent TSPOgp91 ${ }^{\text {phox }}$, TSPO-p22 $2^{\text {phox }}$, and TSPO-VDAC PLA interactions, respectively, in microglia. The different TSPO-protein interactions are visible throughout the cell as single dots representative of molecular interactions between the proteins providing further support of an association of TSPO with gp91 ${ }^{\text {phox }}$, p $22^{\text {phox }}$, and VDAC. Figure $3 \mathrm{~d}$ depicts the PLA quantitative results. The results showed specific TSPO associations with the NOX2 subunits gp91 $1^{\text {phox }}$ and p22 $2^{\text {phox }}$, as well as VDAC, confirming the co-immunoprecipitation and immunofluorescence confocal imaging results. Notably, we did not observe an effect of LPS activation in decreasing the number of gp9 $1^{\text {phox }}$ and $\mathrm{p} 22^{\text {phox }}$ interactions with TSPO using the PLA assay (Additional Table S8). The lack of an effect of LPS activation using the PLA assay was due to the fact that the PLA assay is dependent on the primary antibody concentration which was specifically optimized to detect a small fraction of the total protein-protein interactions occurring within a cell.

The Mitochondria-Associated Endoplasmic Reticulum Membrane (MAM): a Putative Site for a TSPO Association with gp91 ${ }^{\text {phox }}-$ p22 $2^{\text {phox }}$ in Primary Microglia It is well established that TSPO and VDAC are proteins that are highly expressed at the outer mitochondrial membrane and that $\mathrm{gp} 91^{\text {phox }}$ and $\mathrm{p} 22^{\text {phox }}$ mature and form the $\mathrm{Cytb}_{558}$ heterodimer in the ER. We have previously proposed that these proteins are likely interacting at the mitochondria-associated ER membrane or MAM [55]. To examine whether TSPO is found at the MAM, we performed immuno-gold electron microscopy (IGEM) of TSPO in LPSand vehicle-treated primary microglia. We used an IGEM approach because the microglia number from culturing is low and not sufficient to obtain enough pure MAM fraction to perform Western blot to confirm purity and assess proteins of interest. Figure 4 depicts images of microglia under normal culture conditions (Fig. 4a, c, d), and after LPS treatment (Fig. 4b). A negative control, that is, the absence of the TSPO primary antibody for the TSPO-IGEM studies is provided in Supplementary Fig. S9. The results presented in Fig. $4 a, b$ demonstrate, as expected, an abundant TSPO labeling of the outer mitochondrial membrane (see yellow stars). With LPS treatment, there is an apparent increase in TSPO labeling in the mitochondria (see yellow stars), as well as TSPO labeling in other subcellular compartments such as the plasma membrane (arrows in Fig. $4 \mathrm{~b}$ ) and throughout the cytoplasm. Figure $4 \mathrm{c}$ and $\mathrm{d}$ are higher magnification images of non-activated microglia indicating the presence of TSPO at the MAM (see arrows in Fig. 4c) as well as in the ER (yellow arrow heads in Fig. 4d) and at or just below 
a
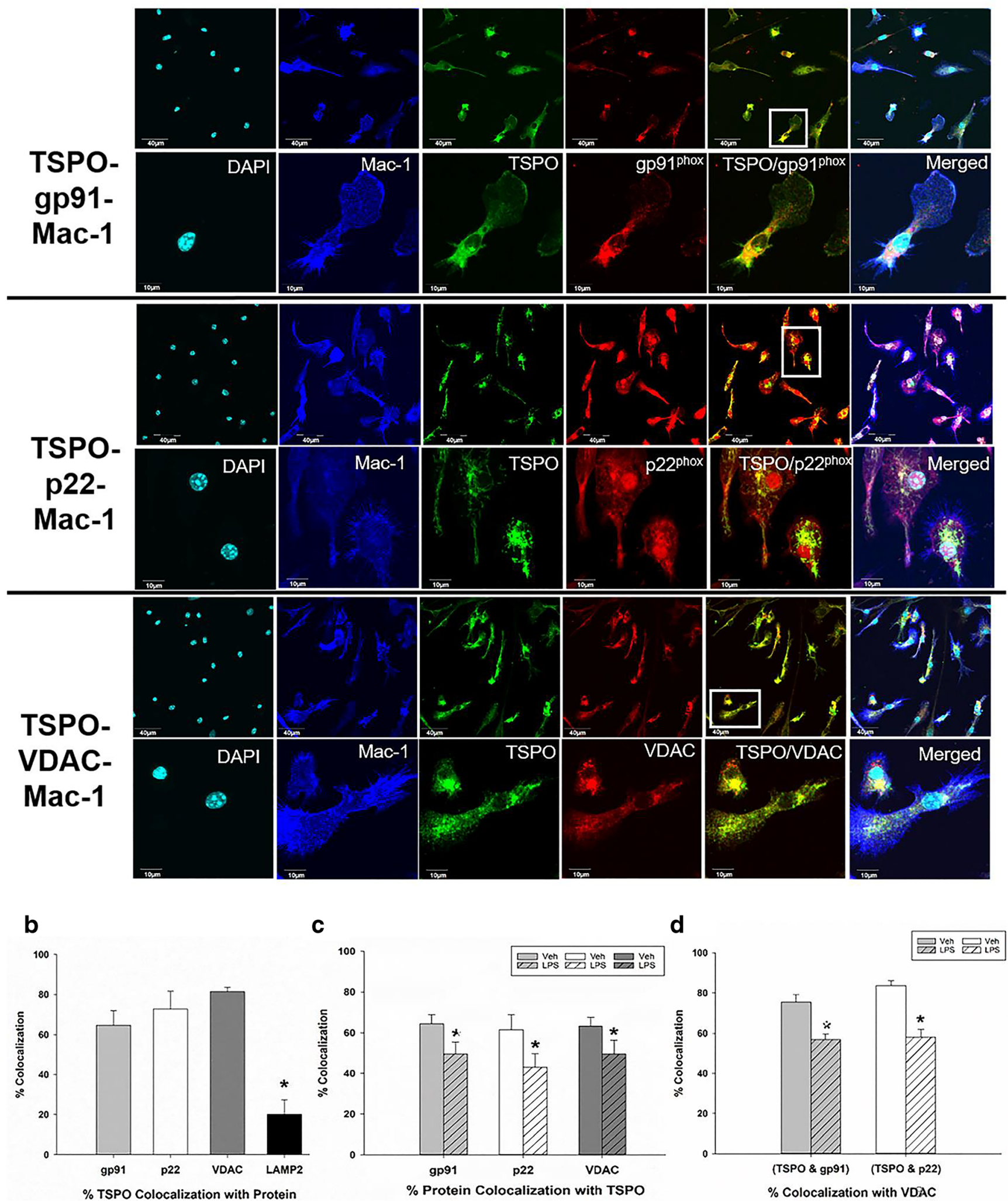

the plasma membrane (arrows in Fig. 4d). These images confirm that TSPO is highly expressed in the outer mitochondria membrane as previously described. However, our results also provide evidence that TSPO is present in other subcellular compartments such as the plasma membrane and the MAM (see arrows in Fig. $4 b-d)$. 
Fig. 2 Immunocytochemistry and confocal imaging of TSPO colocalization with gp91 ${ }^{\text {phox }}, \mathrm{p} 22^{\text {phox }}$, VDAC, and LAMP-2 and effect of LPS activation in primary microglia. a Triple-label immunofluorescent confocal images of TSPO colocalization with gp91 ${ }^{\text {phox }}, \mathrm{p} 22^{\text {phox }}$, or VDAC in primary microglia (Mac-1 labeled) cells. Confocal images show that TSPO colocalizes with gp $91^{\text {phox }}, \mathrm{p} 22^{\text {phox }}$, and VDAC in primary microglia. Images in upper panels are at a low magnification: scale bar $=40 \mu \mathrm{m}$. Cells in white boxes were selected to be expressed at a higher magnification: scale $b a r=10 \mu \mathrm{m}$ (lower panel). b Analyses of protein pair signal colocalization revealed that TSPO has a high degree of colocalization with gp $91^{\text {phox }}(64.68 \%)$, p $22^{\text {phox }}(72.82 \%)$, and VDAC $(81.48 \%)$ and a lower level of colocalization $(20.13 \%)$ with the lysosomal marker, LAMP-2 in vehicle-treated microglia. Analysis of variance with Tukey's post hoc tests shows a significant effect of protein colocalization with TSPO $\left(F_{3,6}=9.8 ; p=0.0006\right)$ where TSPO colocalization with LAMP-2 is significantly lower than with gp $91^{\text {phox }}, \mathrm{p} 22^{\text {phox }}$, and VDAC $(*=p<0.01)$. c The percentage of gp91 ${ }^{\text {phox }}, \mathrm{p} 22^{\text {phox }}$, and VDAC that colocalized with TSPO decreased when microglia were activated with $100 \mathrm{ng} / \mathrm{mL}$ of LPS for $18 \mathrm{~h}$ relative to vehicle conditions (\% gp91 with TSPO: $p=0.004 ; \%$ p22 with TSPO: $p=0.002 ; \%$ VDAC with TSPO: $p=0.003)$. These results indicate that microglia activation disrupts TSPO's association with gp91 $1^{\text {phox }}, \mathrm{p} 22^{\text {phox }}$, and VDAC. d Further analysis of signal colocalization indicates that under LPS-stimulated conditions, TSPO associated with gp91 and TSPO associated with p22, exhibit significantly decreased colocalization with VDAC suggesting a movement from the mitochondria to other cellular compartments (\% (TSPO with gp91)/VDAC: $p<0.001 . \%$ (TSPO with p22)/VDAC: $p=0.004)$. Data are expressed as mean \pm s.e.m. $n=5-7$ independent experiments with $>35$ microglia counted per treatment condition per experiment. $n=3$ independent experiments for TSPO/LAMP-2 labeling with $>35$ microglia counted per treatment condition per experiment. Student's paired $t$ test was performed; $* p<0.05$ compared to vehicle-treated microglia

\section{Modulation of Plasma Membrane TSPO Expression by} Reactive Oxygen Species in Primary Microglia The results of the TSPO subcellular localization studies using TSPO-IGEM in vehicle and LPS-treated microglia suggest that based on the activation state of microglia, there may be an increase in the surface expression of TSPO (Fig. 4). TSPO has been historically known as an outer mitochondrial membrane protein as confirmed by our TSPO-IGEM studies in primary microglia (Fig. 4), although several reports have noted that TSPO is also present at the plasma membrane $[56,57]$ including our present work using TSPO-IGEM (Fig. 4). Since ROS production is one of the known effects of microglia activation, we hypothesized that an acute burst of ROS may alter the cell surface expression of TSPO. To generate an acute burst of ROS, we exposed primary microglia immediately after harvesting to the ROS inducer tert-butyl hydroxyperoxide (TBHP; $400 \mu \mathrm{M}$ ) for $45 \mathrm{~min}$ at $37^{\circ} \mathrm{C}$. The results in Fig. 5a show representative flow cytometry dot plots demonstrating that exposure to TBHP increase ROS levels (Fig. 5b) as well as surface TSPO expression (Fig. 5c) in live microglia selected by SYTOX® staining (see gating scheme in Supplementary Fig. S10). Furthermore, the ROS-induced increase in surface TSPO expression was abrogated by the ROS scavenger $N$ acetyl cysteine (NAC; $5000 \mu \mathrm{M}$ for $1 \mathrm{~h}$ at $37^{\circ} \mathrm{C}$ ) (Fig. $5 \mathrm{~b}, \mathrm{c}$ ).
TSPO Colocalization with $\mathrm{gp} 91^{\text {phox }}$ in Murine Brain Tissue The studies presented above were performed in primary microglia. However, to show that the TSPO-NOX2 subunit colocalization also occurs in brain tissue, we performed triple-label immunofluorescence confocal imaging studies of TSPO, gp91 ${ }^{\text {phox }}$, and Mac-1 in mouse brain tissue. These studies were performed in the brain of Sandhoff disease transgenic and wildtype mice. We used this animal model because we have previously characterized the TSPO response in microglia and astrocytes that occurs as a result of progressive neurodegeneration in this murine model of Sandhoff disease [47]. Panel a in Fig. 6 shows that TSPO and gp91 ${ }^{\text {phox }}$ colocalize in microglia in the mouse brain. Thus, the TSPOgp91 ${ }^{\text {phox }}$ colocalization not only occurs in primary microglia in culture but also in situ in the brain. Furthermore, the TSPOgp91 ${ }^{\text {phox }}$ colocalization in the thalamus of Sandhoff disease mice increases as a function of age and progression of neurodegeneration in this preclinical animal model of neurodegeneration (Fig. 6b). It should be noted that given this is a model of neurodegeneration, and that there has been documentation of a compromised blood brain barrier in this murine model of Sandhoff's disease [58]. It is possible that some cells labeled with Mac-1 could also represent infiltrating peripheral immune cells that would also stain positive for Mac-1.

\section{Bioinformatics Reveal Structural Elements for Heme or Porphyrin Transit from the Intermembrane Space to the Cytosolic Surface of the Outer Mitochondrial Membrane The} relevance of the proposed TSPO-NOX2 interaction may be founded in a fundamental element of NOX2 function, heme. Heme biosynthesis is finalized within mitochondria [59], and NOX2 subunits have shown localization on ER-derived membranes including phagosomes, specialized endosomes ("redoxisomes"), and at the leading edge of lamellipodia [60]. Because the contiguous nature of ER-mitochondrial physiology [61], we employed bioinformatic structural analyses to determine if TSPO may provide a conduit for heme to reach gp65, the heme-accepting immature precursor of gp91 ${ }^{\text {phox }}$. Using SWISS-MODEL workspace [48], we modeled human TSPO (hTSPO) sequence (Uniprot Identifier: P30536-1) onto a known crystal structure for mouse TSPO (mTSPO) with a diagnostic ligand, PK11195, bound to a putative porphyrin-binding site (PDB: 2mgy.1) [62, 63]. The structural modeling produced a transmembrane protein structure with five helices, a loop on the cytosolic surface of the outer mitochondrial membrane (OMM), a short $\mathrm{N}$-terminal region residing in the intermembrane space (IMS), and a longer C-terminal region extending into the cytosol (Fig. 7a). This structure was similar to previously reported monomeric structures of TSPO in other species [62-65]. An analysis of the primary sequence and putative structure of hTSPO were examined for the presence of hallmark heme-binding motifs, and none were found; however, not all heme-interacting 


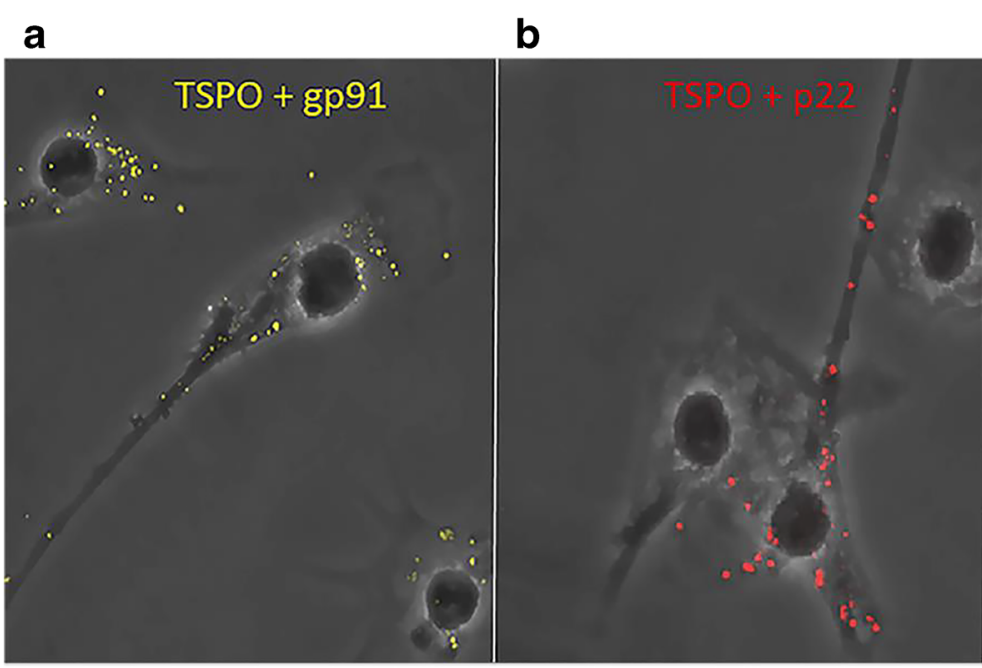

\section{C}

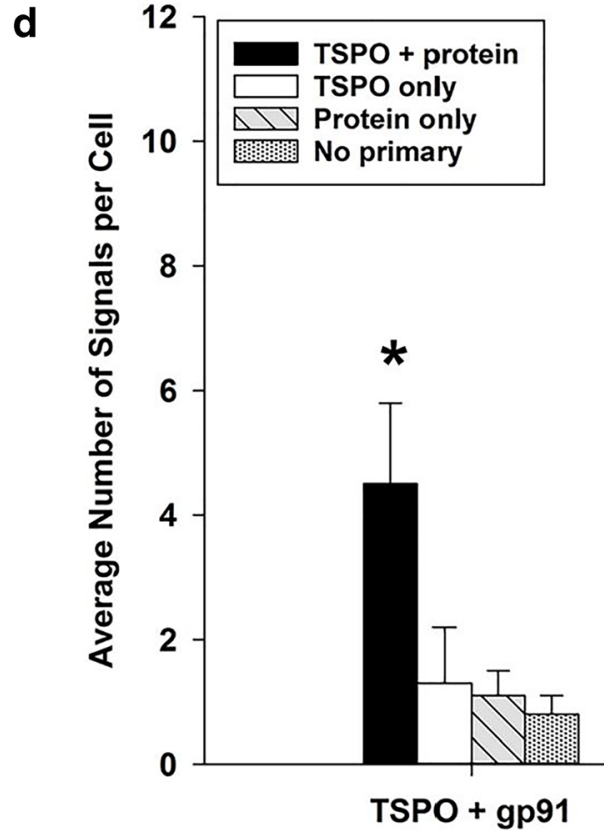

Fig. 3 Proximity ligation assay (PLA) supports a TSPO interaction with gp9 $1^{\text {phox }}, \mathrm{p} 22^{\text {phox }}$, and VDAC in primary microglia. a-c Representative PLA phase and pseudo-colored confocal images of protein pair interactions (colored dots) in microglia: TSPO + gp91 (a); TSPO + p22 (b); TSPO + VDAC (c). The images indicate that TSPO interacts with gp $91^{\text {phox }}, \mathrm{p} 22^{\text {phox }}$, and VDAC respectively supporting the coimmunoprecipitation and immunocytochemistry colocalization results. d Quantification of average number of protein pair signals per microglia in vehicle conditions at $18 \mathrm{~h}$. PLA experiments confirms that TSPO interacts with the NOX2 subunits gp91 ${ }^{\text {phox }}$ and $\mathrm{p} 22^{\text {phox }}$, as well as the

proteins contain these elements [66]. Thus, the structure and sequence were used with the HemeBind software [50] to ascertain if residues capable of binding heme were present within the protein. According to the HemeBind analysis, 18 amino acids were identified that could interact with heme (Fig. 7, table inset), and these amino acids were restricted to helices 2,3 , and 4 , but three additional amino acids (W33, Y34, and L37) resided on the cytosolic loop (Fig. 7b). The triplet was part of a larger conserved WYXXLXKP motif among
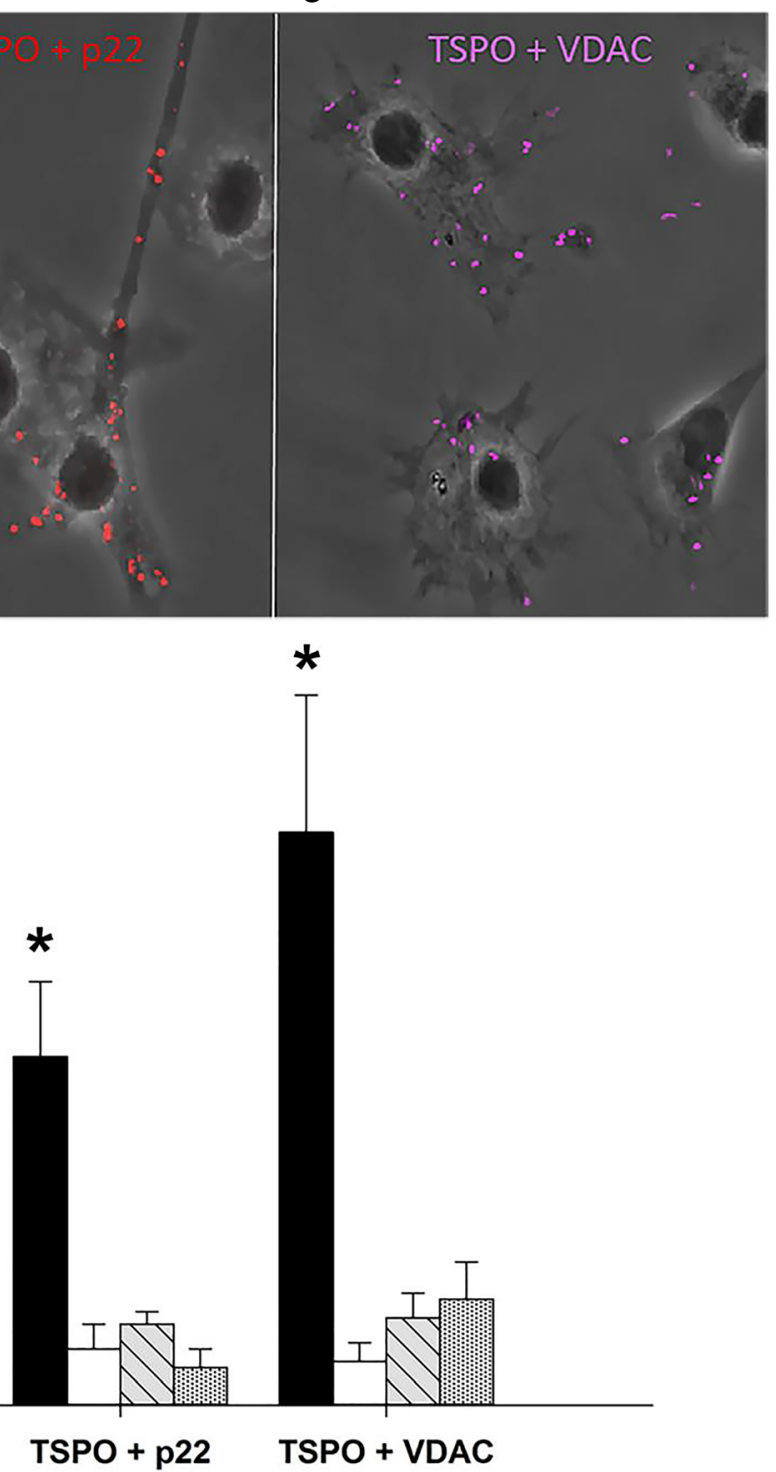

mitochondrial protein, VDAC. Imaging and quantification included negative controls for labeling conditions of single antibody only, as well as no primary antibody, to ensure signal specificity. Data are expressed as mean \pm s.e.m. $n=4-7$ independent experiments with $>30$ cells counted per treatment and per labeling condition. One-way ANOVA across labeling conditions was performed; (TSPO+gp91: $F_{3,17}=8.193, p=0.002$; TSPO+p22: $F_{3,11}=11.108, p=0.003$; TSPO+VDAC: $F_{3,14}=9.979$, $p=0.002) . * p<0.05=$ significantly different relative to all other conditions within a protein pair group

hTSPO, mTSPO, and TSPO from Rhodobacter sphaeroides (rTSPO) that was crystalized with protoporphyrin IX (PPIX) (Supplemental Fig. S11) [49]. Mapping the PPIX binding site of rTSPO onto hTSPO indicates that Y34 of the loop WYXXLXKP motif extends towards PPIX, while W33 faces the cytosol (Fig. 7b). While the porphyrin-binding site and a cytosolic facing element could be present, there was little evidence to support how a molecule might reach portions of TSPO near the OMM. Continued analysis of putative heme- 

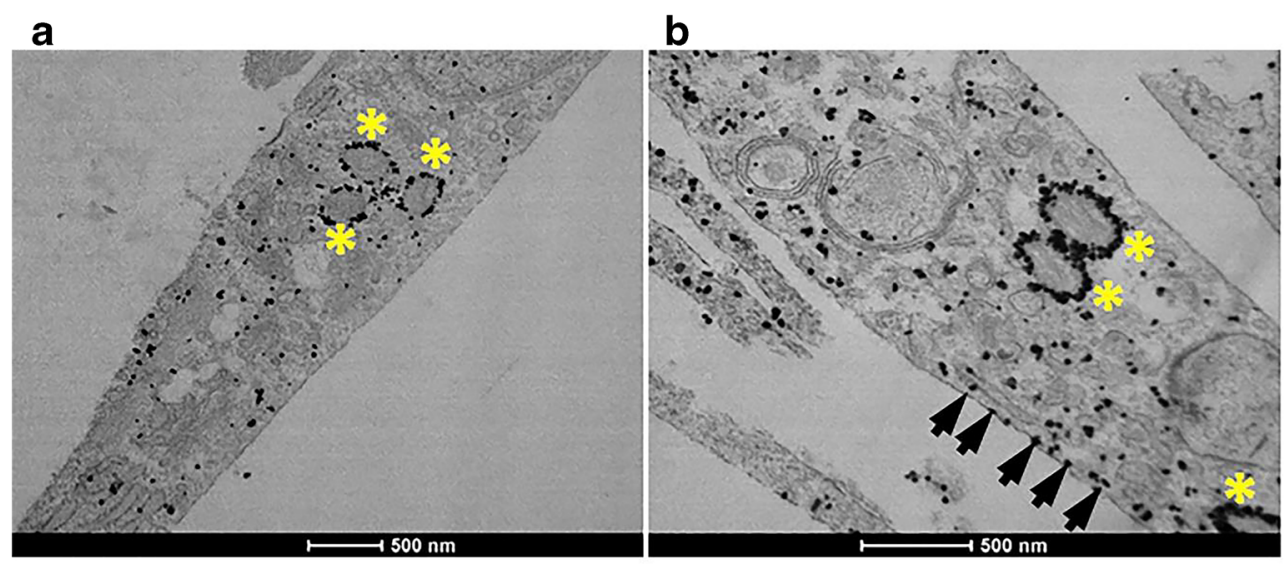

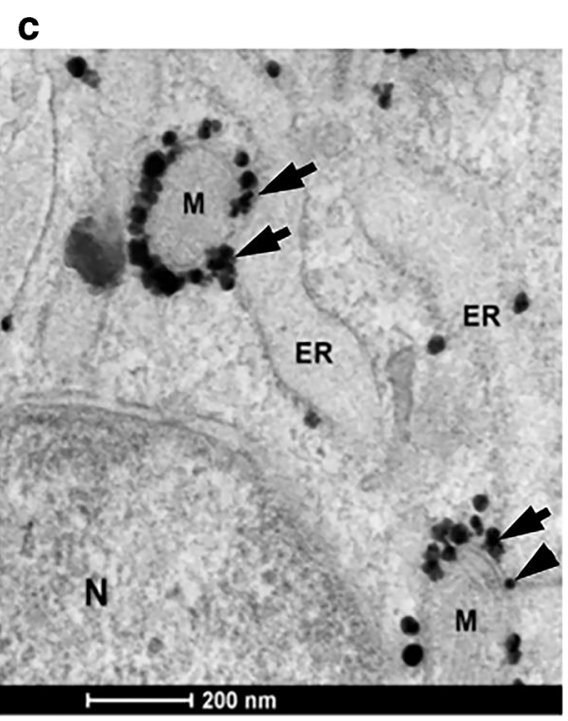

Fig. 4 Immuno-gold electron microscopy of TSPO in primary microglia. a Immuno-gold electron microscopy of TSPO in vehicle-treated microglia confirms a high level of TSPO expression in mitochondria (yellow stars). Black dots = TSPO. $\mathbf{b}$ TSPO expression in microglia activated with LPS $(100 \mathrm{ng} / \mathrm{mL})$ for $18 \mathrm{~h}$. There is an apparent increase in TSPO expression. TSPO labeling is seen at the mitochondria, as well as other subcellular compartments including at or just below the plasma d

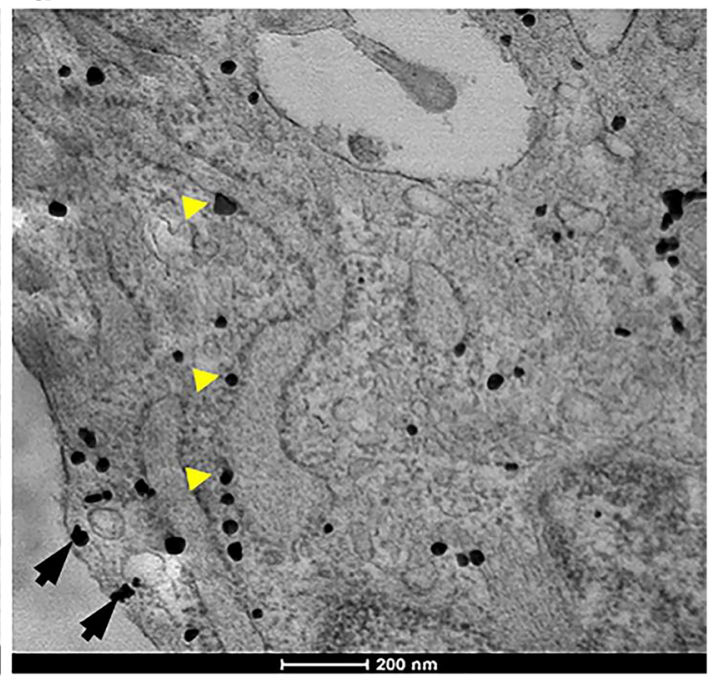

membrane (black arrows). $\mathbf{c}$ High magnification imaging of TSPO expression in non-activated microglia indicates TSPO localization in the endoplasmic reticulum (ER) and at the mitochondria-associated ER membrane or MAM (black arrows). $\mathrm{N}=$ nucleus; $\mathrm{M}=$ mitochondria; $\mathrm{ER}=$ endoplasmic reticulum. d High magnification imaging of TSPO expression in non-activated microglia shows TSPO localization at the ER (yellow triangles) and at or just below the plasma membrane (black arrows) interacting residues unearthed a motif in the IMS of hTSPO with surface residues that may bind heme; these include Y65, L66, W68, and L71, which are part of a conserved WXXLYXXM motif at the bottom of helix 2 near an IMS loop. In fact, modeling predicts that W68 can extend into the IMS away from helix 2 towards making it available to proteins or molecules in the IMS (Fig. 7c). To discern if the modeled structure could provide insight into any connectivity between the proposed IMS WXXLYXXM heme-loading motif, the porphyrin-binding site, and the OMM WYXXLXKP site, we modeled the surface topology of hTSPO to determine if structural elements were present to connect these elements (Fig. 7d (i)). We used predicted protein hydrophobicity (Fig. 7d (ii)), as an indication of nonpolar amino acids, and aromaticity (Fig. 7d (iii)), to demonstrate surface aromatic amino acids on hTSPO. Both nonpolar and aromatic amino acids have been shown to be critical to heme-interactions in heme-proteins lacking strong, hallmark heme-binding motifs [66]. Our examination found that there were aspects of protein hydrophobicity, from the presence of nonpolar amino acid involved in potential heme-interactions stretched from the IMS to the porphyrin-binding pocket (Fig. 7d (ii), red). This trough included predicted heme-interacting residues G54, L56, L89, L112, V115, and A119. The area also surrounded polar amino acids M60, N92, and S116 also implicated in heme-binding by our bioinformatics approach. Next, the aromaticity revealed a significant aromaticity near the porphyrinbinding pocket (Fig. $7 \mathrm{~d}$ (iii), blue), but there were also 


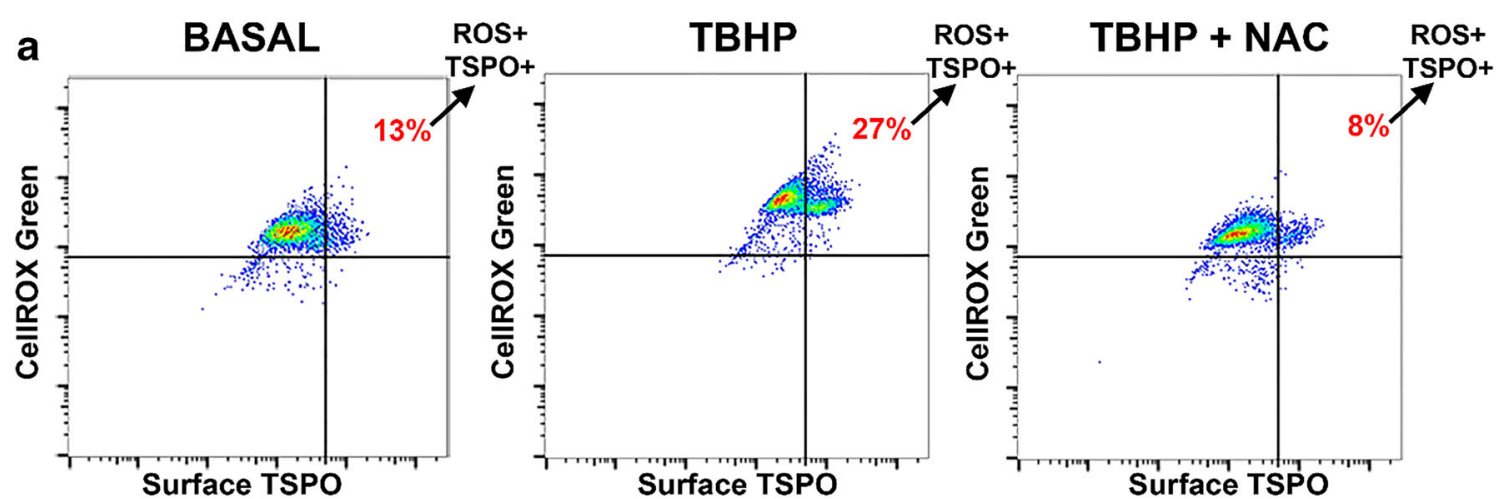

b

Fig. 5 Reactive oxygen species (ROS) modulates surface expression of TSPO in primary microglia cells. a Representative flow cytometry dot plots of surface TSPO and CellROX® fluorescence in live primary microglia cells that were treated with and without $N$-acetyl cysteine (NAC), a ROS scavenger followed by tert-butyl hydroperoxide (TBHP), an ROS inducer. Percentage of surface TSPO expression (b) and mean

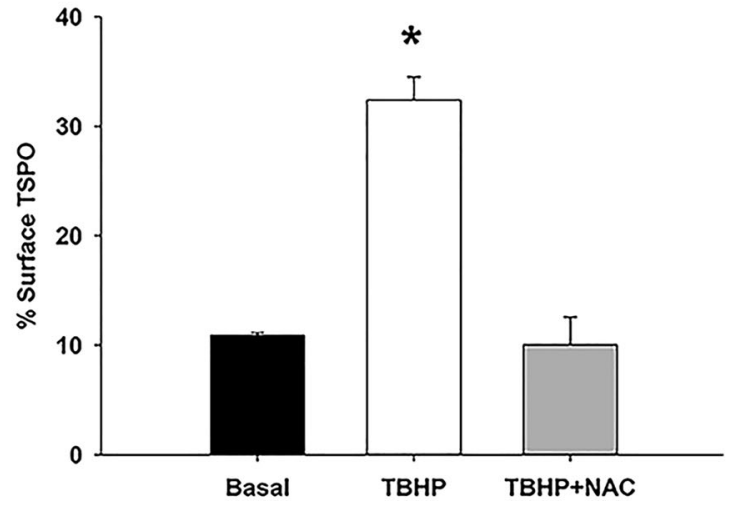

C

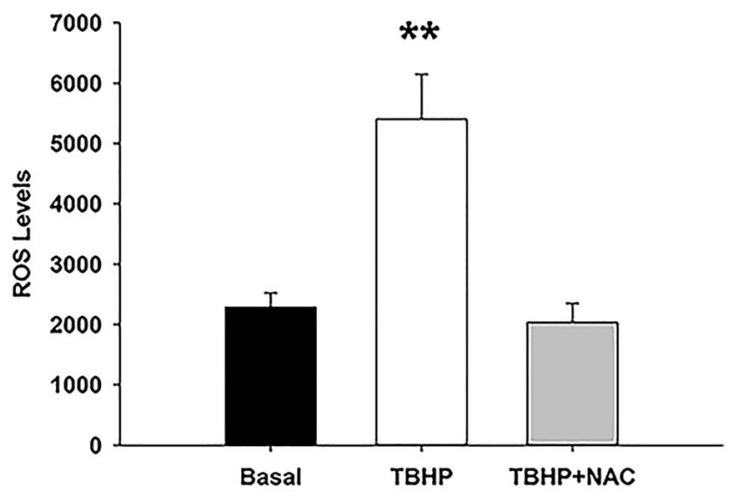

fluorescence intensity (MFI) of ROS levels (c) with TBHP, \pm NAC treatment. Surface TSPO expression and ROS levels increase with TBHP, while NAC treatment inhibited ROS and surface TSPO caused by TBHP. Data are expressed as mean $\pm \operatorname{sem} n=3$ independent experiments: One-way ANOVA was performed; $* p=0.0003, F_{2,6}=44.2$ compared to basal levels; ** $p=0.0046, F_{2,6}=15.1$ compared to basal levels

b
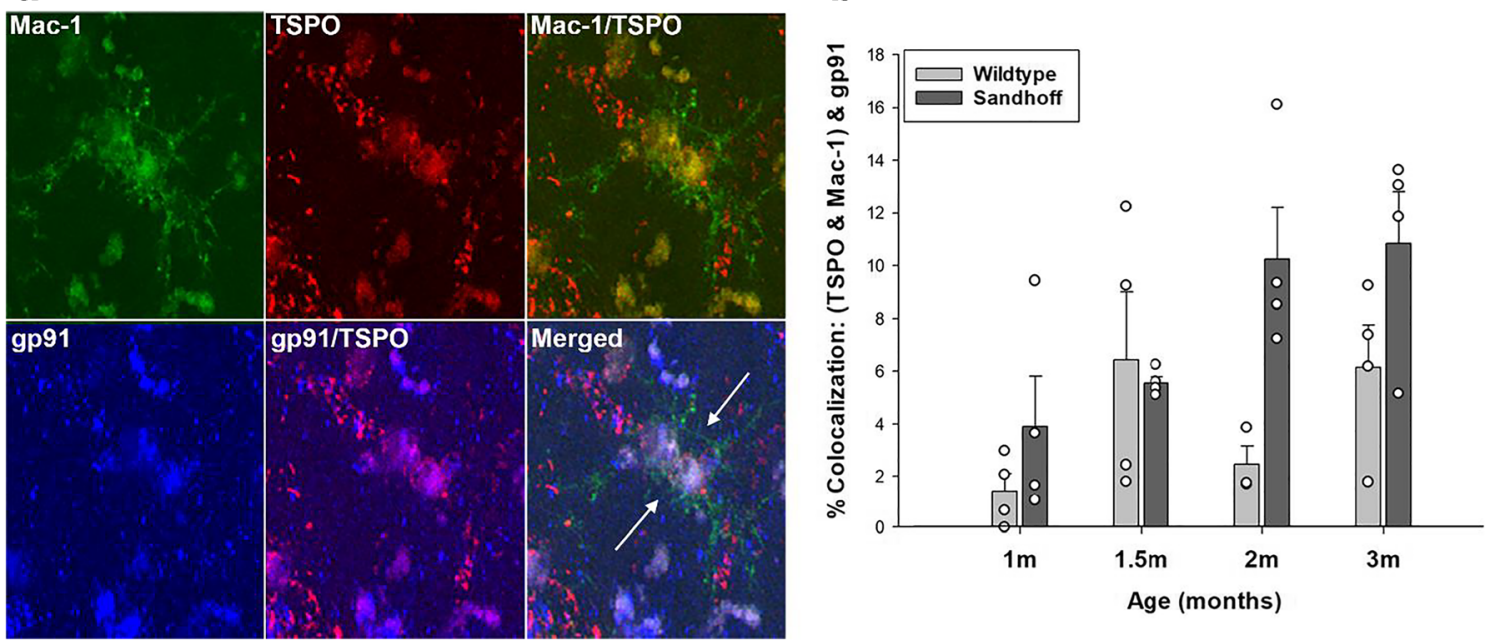

Fig. 6 In situ colocalization of TSPO with gp9 $1^{\text {phox }}$ in murine brain microglia. a Representative triple labeled immunofluorescent confocal images in the thalamus of a 2-month old Sandhoff disease mouse at $60 \times$ with $1.6 \times$ zoom. Imaging confirmed that the TSPO signal colocalizes with the gp91 ${ }^{\text {phox }}$ signal in Mac-1 labeled microglia. b Quantification of percent colocalization of TSPO with gp91 ${ }^{\text {phox }}$ in microglia in the thalamus of Sandhoff disease mice compared to wildtype as a function of age.
The data indicates that the TSPO-gp91 ${ }^{\text {phox }}$ interaction increases as a function of age and progression of neurological disease (age: $F_{3,7}=$ 4.257, $p=0.017$; genotype: $F_{1,7}=11.081, p=0.003$; age $\times$ genotype: $F_{3,7}=1.548, p=0.232$ ). Data are expressed as mean \pm s.e.m. $n=4$ independent animals and experiments per group, except for the 2-month old wildtype group which has $n=3$ due to one animal being excluded as an outlier ( $>3$ standard deviations from the mean) 
a

b

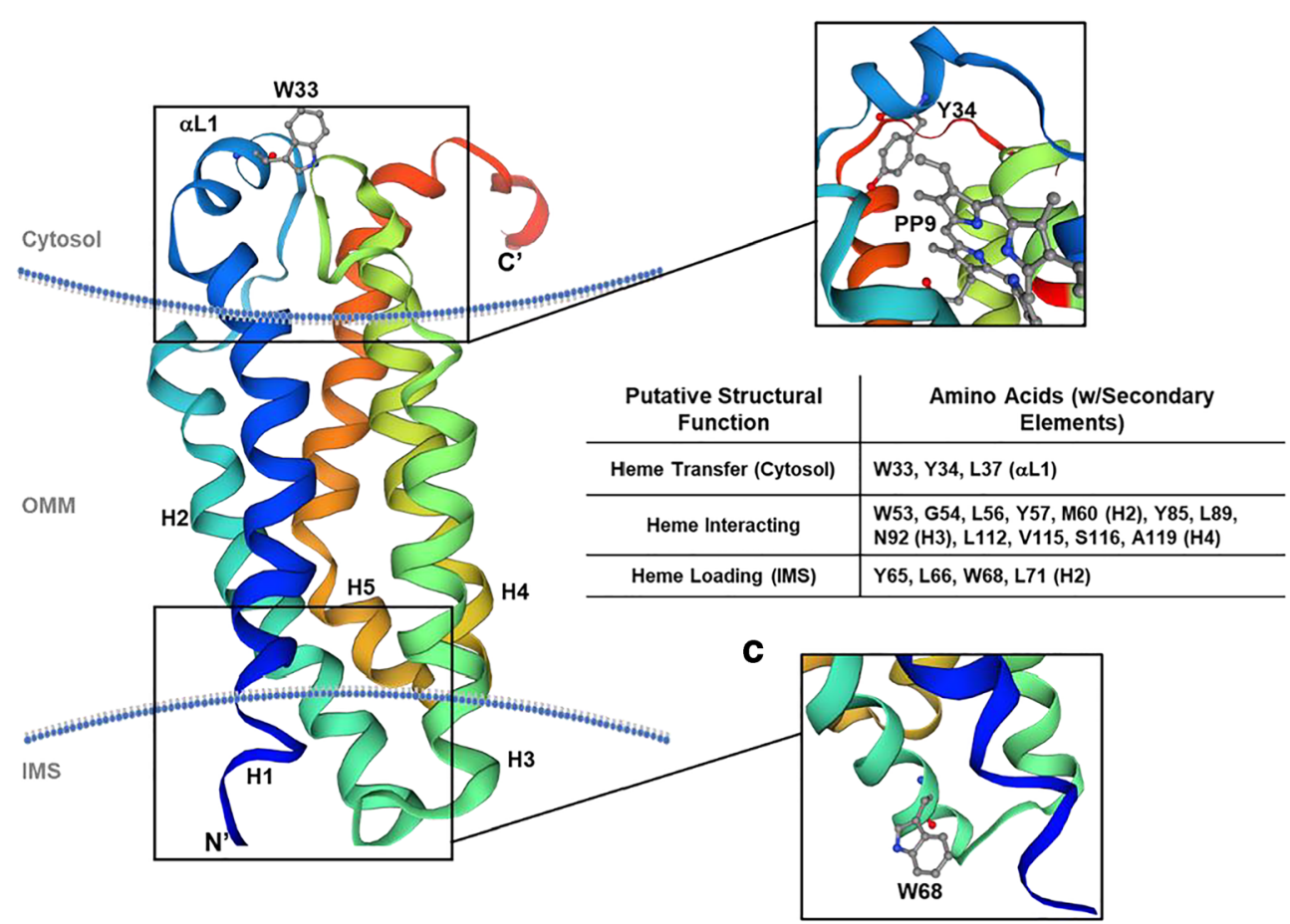

d

(i)

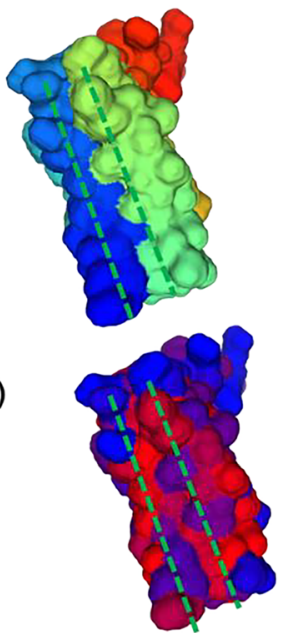

(iii)

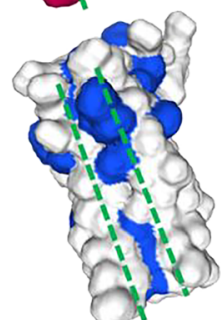

Fig. 7 Bioinformatics-based modeling of the hTSPO monomer and putative heme-binding capabilities. (a) A ribbon diagram of hTSPO mapped to mouse TSPO structure (PDB: 2mgy.1) with a-helices color coded (blue: Helix 1, blue-green: Helix 2, green: Helix 3, green-yellow: Helix 4, orange-red: Helix 5). The $\mathrm{N}$-terminus $\left(\mathrm{N}^{\prime}\right)$ is labeled along with the $\mathrm{C}$-terminus $\left(\mathrm{C}^{\prime}\right)$ and conserved tryptophan-33 (W33) in the cytosolic a-loop. (b) immediately below W33 is the proposed porphyrin-binding site identified in crystal structures of Rhodobacter sphaeroides TSPO illustrated by the appearance of protoporphyrin IX (PP9). The conserved a-loop motif of WYXXLXKP, wherein W33, Y34, and L37 of hTSPO were identified as potential heme-interacting residues. Using the
HemeBind software and the sequence and modeled structure of hTSPO, we were able to identify amino acids with the potential for heme binding that were not implicated in porphyrin-binding in previous models. Including a motif (WXXLYXXM) in the intermembrane space of the mitochondria that could be the site of heme loading at the close of biosynthesis typified by the presence of W68 in hTSPO at the bottom of helix 2 (c). (d) An examination of the predicted protein surface topology using the same colors as the ribbon structure reveal a groove or trough between helices 1 and 3 (i). This trough has stretches of hydrophobicity (ii, red) and aromaticity (iii, blue) that resemble traits of other heme binding proteins without conserved or strong heme-binding motifs increased levels of aromaticity surrounding the proposed heme-loading WXXLYXXM motif and the cytosolic loop WYXXLXKP motif above the porphyrin-binding site (Fig. 7d (iii), blue). Taken together, these results demonstrate a strong possibility for hTSPO to interact with heme and/or other porphyrins, and there may be physicochemical properties that may allow heme to move from the IMS to the cytosol along the lateral surface of the protein monomer.

\section{Discussion}

There are several novel findings resulting from the present study. First, using three different experimental techniques, we demonstrate a novel interaction of TSPO with the NOX2 subunits gp $91^{\text {phox }}$ and $\mathrm{p} 22^{\text {phox }}$ in primary microglia. We also confirmed that TSPO associates with VDAC as previously described [51, 52]. Based on our TSPO-IGEM results, we confirm that TSPO is present at the outer mitochondria membrane, but also at other subcellular compartments such as the MAM and the plasma membrane. We have hypothesized that the MAM may be a subcellular site where TSPO may associate with the NOX2 subunits (Fig. 4) since the MAM is a site of ER-mitochondria communication [61].

Second, we show that the TSPO association with gp9 $1^{\text {phox }}$ and $\mathrm{p} 22^{\text {phox }}$ appears to be disrupted by LPS treatment of microglia. This is demonstrated by the fact that the relative amount of $\mathrm{gp} 91^{\text {phox }}$ and $\mathrm{p} 22^{\text {phox }}$ protein that coimmunoprecipitates with TSPO in LPS-treated microglia decreases relative to vehicle-treated microglia despite the fact that the LPS treatment of microglia increases TSPO, gp91 ${ }^{\text {phox }}$, and $\mathrm{p} 22^{\text {phox }}$ protein levels in the input fraction (Figs. 1 and 2). It is possible that the TSPO association with gp91 ${ }^{\text {phox }}$ and $\mathrm{p} 22^{\text {phox }}$ is transient and depends on the state of microglia activation since the TSPO interaction with VDAC did not change with LPS treatment (Fig. 1). Parenthetically, the latter is consistent with other studies in which cellular treatments that increase TSPO expression do not change VDAC levels 
[67] and VDAC expression does not change in TSPO-KO mice [68].

Third, we provide evidence that exposing microglia to an acute burst of ROS increases the cell surface expression of TSPO, an effect that is abrogated by an ROS scavenger (Fig. 4 and Fig. 5). Consistent with our current findings that TSPO is present in the cell surface of primary microglia, a recent study using the BV2 microglia cell line has shown that TSPO is present in the plasma membrane using differential centrifugation and analysis of subcellular fractions by Western blot [69]. This study also showed that LPS stimulation of BV2 cells increased TSPO levels in mitochondria by approximately $30 \%$ but increased plasma membrane TSPO by $100 \%$ with minimal levels of TSPO present in cytosolic or nuclear fraction with or without LPS. The functional significance of an ROS- or LPS-induced increase in TSPO cell surface expression is not known, but we hypothesize that it may be due to the association of TSPO with the NOX2 subunits. What is not known, is the subcellular source of the increase in cell surface TSPO observed following a burst of ROS and following LPS treatment. Future studies will specifically address this important question. Finally, we provide evidence that the TSPOgp9 $1^{\text {phox }}$ subunit colocalization is also observed in brain tissue microglia from a murine model of neurodegeneration suggesting that these associations not only occur in primary microglia but also in the brain in situ (Fig. 6).

While the current study provides multiple lines of evidence supporting an association of TSPO with gp $91^{\text {phox }}, \mathrm{p} 22^{\text {phox }}$, and VDAC, it has limitations. First, most of the studies presented here are in vitro studies and there is no in vitro culturing method that can recapitulate all of the hallmark features of neonatal or adult microglia in brain tissue [70]. Additionally, while in vitro studies are useful for defining mechanism(s) and determining cellular specificity of protein associations, as we have done in the present study, they also have limitations given that microglia are operating without feedback from other brain cells such as neurons and astrocytes. The present work in primary microglia from neonatal mouse brain is an important starting point in order to understand the function of TSPO which is currently unknown in microglia. Using primary microglia is an appropriate approach and a significant improvement over using cell lines which can respond differently to certain modes of activation relative to primary microglia $[71$, 72]. Finally, while there is evidence that neonatal microglia may differ in behavior from adult microglia [73], microglia from the adult brain are more limited in number than microglia from the neonatal brain. Thus, despite the limitations outline, using neonatally derived microglia, is a suitable starting point to begin to understand the function of TSPO.

Evidence of a TSPO-NOX interaction has also recently been described by Gatliff et al., [51]. The study by these investigators indicates that TSPO modulation of mitochondrial calcium signaling via VDAC activates another NOX subtype, the calcium-dependent NOX5. However, NOX5 is not expressed in phagocytic cells including microglia [32, 74, 75]. Thus, the TSPO-mediated calcium-dependent activation of NOX5 is different from our present study in which we demonstrate an association between TSPO and the NOX2 subunits gp $91^{\text {phox }}$ and $\mathrm{p} 22^{\text {phox }}$. Another distinctive difference between the work of Gatliff et al. [51] and ours is that they used cell systems such as mouse embryonic fibroblasts, canine mammary gland epithelial cells, and the neuronal cell line SHSY5Y compared to primary microglia in our study. The cell types used in the Gatliff et al.'s study were in some cases transformed or neuronal cell lines with functions that are different to microglia. It is well established that glial cells (microglia and astrocytes) are the principal contributors of the increase in TSPO levels in the brain neuropil following diverse brain pathologies [3]. Therefore, the TSPO-NOX2 interaction that we have identified in primary microglia is vastly different from the TSPO-mediated, calcium-dependent modulation of NOX5 activity [51].

During the review of our current manuscript, another study was published describing a TSPO-NOX1 interaction [76]. In this study, they find that laser photocoagulation injury of the retina results in activation of resident microglia and increased microglia TSPO levels. The increase in TSPO levels results in a TSPO-mediated increase in cytosolic calcium concentrations essential for the activation of NOX1 with a subsequent increase in extracellular ROS production. The increase in extracellular ROS results in the loss of photoreceptor cells and retinal injury. These two previous studies, along with our current work, indicate a relationship between TSPO and different NOX enzyme subtypes in microglia implicating TSPO in the regulation of NOX activity and ROS production in microglia.

Our current findings raise several important questions on the association of TSPO with gp $91^{\text {phox }}$ and $\mathrm{p} 22^{\text {phox }}$ in primary microglia. One relevant question is the molecular basis for an association between TSPO and NOX2. We previously hypothesized [55] that an association between TSPO and NOX2 subunits may be related to the ability of TSPO to bind both heme [77, 78] and cholesterol [21, 79] and the absolute requirement for heme to dimerize gp $91^{\text {phox }}$ and $\mathrm{p} 22^{\text {phox }}$ to form a functional $\mathrm{Cytb}_{558}$ heterodimer. That is, the NOX2 subunits gp9 $91^{\text {phox }}$ and $\mathrm{p} 22^{\text {phox }}$ that we demonstrate to associate with TSPO are known to dimerize via two heme molecules to form the membrane-bound $\mathrm{Cytb}_{558}$ [33-36]. In the absence of heme, these subunits dissociate and are degraded by the proteasome pathway [34]. Cholesterol is also needed for the NOX2 cytosolic subunits to translocate to the plasma membrane and form an active NOX2 complex [38, 39].

Another question raised by our present study relates to the subcellular site(s) and the functional role(s) of a TSPO-NOX2 interaction. Studies have shown that the MAM is a preferential subcellular site for heme transport to heme acceptor proteins such as cytochrome P450 [80]. TSPO is a protein that is 
present at the MAM (Fig. 4) and binds heme [77, 78]. Thus, it is biologically plausible, and we propose that in microglia (Fig. 8), TSPO may be able to transfer mitochondriasynthesized heme from ferrochelatase $(\mathrm{FECH})$, the enzyme that synthesizes heme in the inner mitochondria membrane to heme-accepting proteins in the ER such as gp65, the precursor of gp91 ${ }^{\text {phox }}$ (Figs. 7 and 8). TSPO is an outer mitochondria membrane protein that is strategically localized in close proximity to FECH in the inner mitochondrial membrane. Based on their subcellular localizations, it is biologically plausible that FECH can directly transfer mitochondriasynthesized heme to TSPO for transport out of mitochondria to heme-accepting proteins such as gp65, the precursor of gp91 ${ }^{\text {phox }}$ in the ER via the MAM (Figs. 7 and 8 ).

What is the evidence that TSPO is a heme-binding protein and that it can translocate heme and porphyrins across the mitochondria membrane? The original description that porphyrins and metalloporphyrins are endogenous TSPO ligands was made over three decades ago [78]. However, there is a paucity of knowledge on the physiological function of TSPO binding of heme and porphyrin. A study using radiolabeled $\left[{ }^{55} \mathrm{Fe}\right]$-heme showed that heme binds to TSPO with high affinity [77]. That is, Cos- 1 cells transfected with TSPO cDNA increased levels of $\left[{ }^{3} \mathrm{H}\right]$-PK11195 binding and $\left[{ }^{55} \mathrm{Fe}\right]$-hemebinding as compared to those transfected with antisense. The binding of $\left[{ }^{55} \mathrm{Fe}\right]$-heme to TSPO in transfected Cos- 1 cells and isolated mouse liver mitochondria had a $\mathrm{Kd}$ of $12 \mathrm{nM}$ and was displaceable by the TSPO ligands PK11195, Ro5-4864, and protoporphyrin IX. The authors summarize that TSPO plays a role in controlling the trafficking of porphyrins and heme by the uptake of the porphyrins and the transport of heme out of the mitochondria. Further support for TSPO having a function in heme transport comes from studies in primitive erythropoiesis [81]. In chickens, a TSPO homolog PBRL is solely expressed during the early development of differentiating erythrocytes and the expression is highly correlated with hemoglobin genes. This study showed that the treatment of chicken embryos with the prototypical TSPO ligand

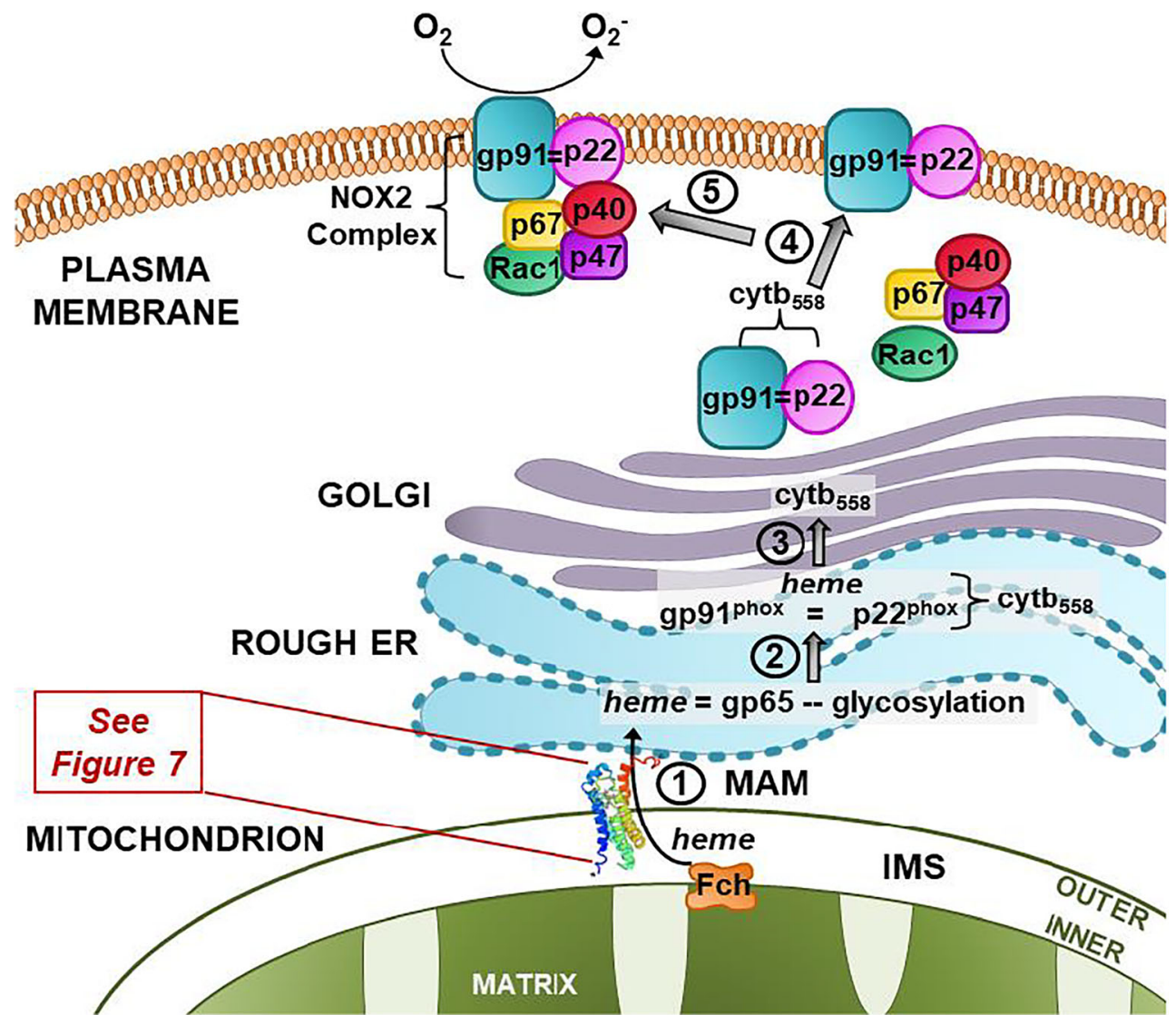

Fig. 8 Working model on the functional significance of a TSPO-NOX2 association in microglia: In this model, we propose that TSPO in the outer mitochondria membrane is able to (1) transfer ferrochelatase synthesized heme from the inner mitochondri membrane to the gp65 precursor of gp91 ${ }^{\text {phox }}$. Once heme has been delivered to gp91 ${ }^{\text {phox }}$, then (2) it is able to dimerize with $\mathrm{p} 22^{\text {phox }}$ in the ER to: (3) form the gp9 $1^{\text {phox }}=\mathrm{p} 22^{\text {phox }}$ and principal catalytic subunit of NOX2, cytochrome $b_{558}\left(\mathrm{Cytb}_{558}\right)$. Once
$\mathrm{Cytb}_{558}$ forms, then (4) it is able to traffic to the plasma membrane/lipid rafts where it remains dormant until an activating event takes place. (5) NOX2 activation promotes the translocation of the cytosolic subunits $\mathrm{p} 40, \mathrm{p} 47, \mathrm{p} 67$, and Rac1 to the plasma membrane to form an active NOX2 complex. MAM: mitochondrial associated membrane; Fch: ferrochelatase; IMS: intermembrane space 
PK11195 resulted in decreased levels of all main embryonic globins without affecting housekeeping genes. The authors indicate that $P B R L$ plays a role in globin protein levels by regulating heme levels during primitive erythropoiesis. They note that collectively their findings support a putative role of $P B R L$ in regulating heme availability for hemoglobin assembly [81].

Another study examining the effect of global TSPO knockout in mice showed that in bone marrow, from all of the hemesynthesizing enzyme measured, there was a selective increase in the gene expression of FECH [68]. The increase in FECH in bone marrow from TSPO-KO mice was associated with a significant increase in bone marrow heme concentration. This study suggests a potential relationship between TSPO and $\mathrm{FECH}$.

Although the physiological basis for a NOX2-TSPO interaction may involve the transfer of heme to NOX2, one obstacle to this hypothesis is the absence of a transit mechanism for heme out of mitochondria to NOX2 on ER-endosomal membranes. While TSPO does possess a porphyrin-binding site, TSPO structures do not appear to have transporter or channel elements. Our model of hTSPO identifies 18 amino acids that may be involved in heme-interactions, but none are part of established heme-binding motifs. This is not unusual for heme-binding proteins [66], as the human intestinal heme transporter lacks the hallmark motifs associated with hemebinding [82]. The organization of three tryptophan residues (W33, W53, and W68) in our hTSPO model reveals a pathway of hydrophobicity and aromaticity on the lateral surface of hTSPO that could participate in heme transit. Tryptophan residues are crucial for heme-interactions and shaping heme protein conformations [83]. In our model, W68 is located at the bottom of helix 2 in the IMS proximal to the last enzyme in heme biosynthesis, FECH [84]. Here, it is anticipated that FECH releases heme into the IMS where it interacts with the W68-containing motif (WXXLYXXM). The heme migrates along a "trough" created by nonpolar and aromatic amino acids, including W53, between hTSPO helices $[50,66]$ en route to the porphyrin-binding pocket (Fig. $7 \mathrm{~d}$ (ii)). Near the porphyrin-binding pocket, the hydrophobicity narrows, and the aromaticity increases moving towards the cytosolic surface of hTSPO (Fig. 7d (iii)). Finally, a motif (WYXXLXKP) containing W33 in the cytosolic a-loop could be the site of heme presentation to gp91 ${ }^{\text {phox }}$ (Fig. 7a). This would likely involve the transfer of heme from the porphyrin-binding pocket to nonpolar L37 and aromatic Y34 and onto W33 (Fig. 7b). We found no histidine residues along the path that might slow or impede heme transit by binding to the molecule $[85,86]$. Consequently, the route identified on the lateral surface of hTSPO would allow heme to move from the IMS to the OMM surface near gp9 $1^{\text {phox }}$.

Collectively, our present findings indicate that TSPO associates with and may be able to regulate the expression of one of the principal NOX2 subunits (i.e., gp91 ${ }^{\text {phox }}$ ) and thus, be able to modulate $\mathrm{Cytb}_{558}$ formation, NOX2 activity, and redox homeostasis in microglia. This working model is consistent with a known function of TSPO in the plant Arabidopsis thaliana in which abiotic stress regulates the homologous $T_{s} O O$ [87]. Abiotic stress in A. thaliana increases TSPO levels. Further, in A. thaliana, TSPO regulates the cell surface expression of the aquaporin PIP2;7 by interacting with PIP2;7 at the ER and Golgi membranes [88]. The function of TSPO in A. thaliana provides a mechanism by which TSPO can modulate PIP2;7 expression at the plasma membrane.

\section{Conclusions}

We provide new evidence of a novel association of TSPO with gp91 ${ }^{\text {phox }}$ and $\mathrm{p} 22^{\text {phox }}$ in primary microglia. We hypothesize that this complex may be present at the MAM to mediate the transfer of mitochondrial heme to the gp65 precursor of gp91 ${ }^{\text {phox }}$. This molecular mechanism would confer a modulatory role for TSPO in the maturation of gp $91^{\text {phox }}$. In this way, TSPO may be able to regulate the heme-containing and principal catalytic subunit of NOX2, its enzymatic activity, ROS production, and microglia redox homeostasis.

Acknowledgments This work was in partial fulfillment of doctoral degree requirements for MKL. We wish to thank Dr. Chun Zhou for generating the HEK293T and J774 Western blots in Supplementary Fig. S1.

Availability of Data and Materials The datasets generated and analyzed during the current study are available from the corresponding author upon reasonable request.

Authors' Contributions Conceptualization: MKL and TRG. Methodology: MKL, SRG, DRB, DJA, and TRG. Formal analysis: MKL and TRG. Investigation: MKL, SRG, JCP, VNP, DRB, JLD, JWC, and DJA. Resources: SRG, DRB, and TRG. Writing-original draft: MKL and TRG. Writing - review and editing: MKL, SRG, DRB, JCP, VNP, JLD, DJA, JWC, and TRG. Imaging: MKL and SRG. Supervision and funding: TRG.

Funding Information This work was supported by grant number ES007062-21 from the National Institute of Environmental Health Sciences to TRG.

\section{Compliance with Ethical Standards}

Conflict of Interest The authors declare that they have no conflict of interest.

Ethical Approval All applicable international, national, and/or institutional guidelines for the care and use of animals were followed. All procedures performed in studies involving animals were in accordance with the ethical standards of the institution at which the studies were conducted (Columbia University and Florida International University Animal Care \& Use Committees). 
Abbreviations TSPO, translocator protein $18 \mathrm{kDa}$; $h T S P O$, human translocator protein $18 \mathrm{kDa}$; $r T S P O$, rat translocator protein $18 \mathrm{kDa}$; $m T S P O$, mouse translocator protein $18 \mathrm{kDa}$; NOX2, NADPH oxidase 2; $L P S$, lipopolysaccharide; $V D A C$, voltage-dependent anion channel; $E R$, endoplasmic reticulum; $R O S$, reactive oxygen species; $K O$, knockout; $m P T P$, mitochondrial permeability transition pore; $C y t b_{558}$, flavocytochrome $\mathrm{b}_{558} ; T B H P$, tert-butyl hydroperoxide; $N A C, N$-acetyl cysteine; $M a c 1$, macrophage integrin 1; $P P 9$ or $P P I X$, protoporphyrin IX; $M A M$, mitochondrial associated membrane; $A L S$, amyotrophic lateral sclerosis; $P N$, post-natal day; $F B S$, fetal bovine serum; IMPC, International Mouse Phenotyping Consortium; EMMA, INFRAFRONTIER/European Mouse Mutant Archive; $I P$, immunoprecipitation; $P V D F$, polyvinylidene difluoride; $T B S$, Tris-buffered saline; $R O I s$, regions of interest; $P L A$, proximity ligation assay; $R C A$, rolling circle amplification; $P F A$, paraformaldehyde; $P B S$, phosphate-buffered saline; $M F I$, mean fluoresence intensity; SEM, standard error of the mean; $L A M P-2$, lysosomal-associated membrane protein-2; IGEM, immunogold electron microscopy; $O M M$, outer mitochondrial membrane; IMS, intermembrane space

Open Access This article is licensed under a Creative Commons Attribution 4.0 International License, which permits use, sharing, adaptation, distribution and reproduction in any medium or format, as long as you give appropriate credit to the original author(s) and the source, provide a link to the Creative Commons licence, and indicate if changes were made. The images or other third party material in this article are included in the article's Creative Commons licence, unless indicated otherwise in a credit line to the material. If material is not included in the article's Creative Commons licence and your intended use is not permitted by statutory regulation or exceeds the permitted use, you will need to obtain permission directly from the copyright holder. To view a copy of this licence, visit http://creativecommons.org/licenses/by/4.0/.

\section{References}

1. Chen MK, Guilarte TR (2008) Translocator protein $18 \mathrm{kDa}$ (TSPO): molecular sensor of brain injury and repair. Pharmacol Ther 118(1):1-17. https://doi.org/10.1016/j.pharmthera.2007.12. 004

2. Papadopoulos V, Baraldi M, Guilarte TR, Knudsen TB, Lacapere JJ, Lindemann P, Norenberg MD, Nutt D et al (2006) Translocator protein $(18 \mathrm{kDa})$ : new nomenclature for the peripheral-type benzodiazepine receptor based on its structure and molecular function. Trends Pharmacol Sci 27(8):402-409. https://doi.org/10.1016/j. tips.2006.06.005

3. Guilarte TR (2019) TSPO in diverse CNS pathologies and psychiatric disease: a critical review and a way forward. Pharmacol Ther 194:44-58. https://doi.org/10.1016/j.pharmthera.2018.09.003

4. Maeda J, Higuchi M, Inaji M, Ji B, Haneda E, Okauchi T, Zhang MR, Suzuki K et al (2007) Phase-dependent roles of reactive microglia and astrocytes in nervous system injury as delineated by imaging of peripheral benzodiazepine receptor. Brain Res 1157: 100-111. https://doi.org/10.1016/j.brainres.2007.04.054

5. Kuhlmann AC, Guilarte TR (1997) The peripheral benzodiazepine receptor is a sensitive indicator of domoic acid neurotoxicity. Brain Res 751(2):281-288. https://doi.org/10.1016/s0006-8993(96) 01409-6

6. Kuhlmann AC, Guilarte TR (1999) Regional and temporal expression of the peripheral benzodiazepine receptor in MPTP neurotoxicity. Toxicol Sci 48(1):107-116. https://doi.org/10.1093/toxsci/48. 1.107

7. Kuhlmann AC, Guilarte TR (2000) Cellular and subcellular localization of peripheral benzodiazepine receptors after trimethyltin neurotoxicity. J Neurochem 74(4):1694-1704. https://doi.org/10. 1046/j.1471-4159.2000.0741694.x

8. Guilarte TR, Nihei MK, McGlothan JL, Howard AS (2003) Methamphetamine-induced deficits of brain monoaminergic neuronal markers: distal axotomy or neuronal plasticity. Neuroscience 122(2):499-513. https://doi.org/10.1016/s0306-4522(03)00476-7

9. Chen MK, Guilarte TR (2006) Imaging the peripheral benzodiazepine receptor response in central nervous system demyelination and remyelination. Toxicol Sci 91(2):532-539. https://doi.org/10.1093/ toxsci/kfj172

10. Chen MK, Baidoo K, Verina T, Guilarte TR (2004) Peripheral benzodiazepine receptor imaging in CNS demyelination: functional implications of anatomical and cellular localization. Brain 127(Pt 6):1379-1392. https://doi.org/10.1093/brain/awh161

11. Gerhard A, Neumaier B, Elitok E, Glatting G, Ries V, Tomczak R, Ludolph AC, Reske SN (2000) In vivo imaging of activated microglia using [11C]PK11195 and positron emission tomography in patients after ischemic stroke. Neuroreport 11(13):2957-2960. https://doi.org/10.1097/00001756-200009110-00025

12. Coughlin JM, Wang Y, Munro CA, Ma S, Yue C, Chen S, Airan R, Kim PK et al (2015) Neuroinflammation and brain atrophy in former NFL players: an in vivo multimodal imaging pilot study. Neurobiol Dis 74:58-65. https://doi.org/10.1016/j.nbd.2014.10. 019

13. Coughlin JM, Wang Y, Minn I, Bienko N, Ambinder EB, Xu X, Peters ME, Dougherty JW et al (2017) Imaging of glial cell activation and white matter integrity in brains of active and recently retired national football league players. JAMA Neurol 74(1):67-74. https://doi.org/10.1001/jamaneurol.2016.3764

14. Zimmer ER, Leuzy A, Benedet AL, Breitner J, Gauthier S, RosaNeto P (2014) Tracking neuroinflammation in Alzheimer's disease: the role of positron emission tomography imaging. J Neuroinflammation 11:120. https://doi.org/10.1186/1742-209411-120

15. Gerhard A, Pavese N, Hotton G, Turkheimer F, Es M, Hammers A, Eggert K, Oertel W et al (2006) In vivo imaging of microglial activation with [11C](R)-PK11195 PET in idiopathic Parkinson's disease. Neurobiol Dis 21(2):404-412. https://doi.org/10.1016/j. nbd.2005.08.002

16. Zurcher NR, Loggia ML, Lawson R, Chonde DB, Izquierdo-Garcia D, Yasek JE, Akeju O, Catana C et al (2015) Increased in vivo glial activation in patients with amyotrophic lateral sclerosis: assessed with [(11)C]-PBR28. Neuroimage Clin 7:409-414. https://doi.org/ 10.1016/j.nicl.2015.01.009

17. Politis M, Su P, Piccini P (2012) Imaging of microglia in patients with neurodegenerative disorders. Front Pharmacol 3:96. https:// doi.org/10.3389/fphar.2012.00096

18. Kuszpit K, Hollidge BS, Zeng X, Stafford RG, Daye S, Zhang X, Basuli F, Golden JW et al (2018) [(18)F]DPA-714 PET imaging reveals global neuroinflammation in Zika virus-infected mice. Mol Imaging Biol 20(2):275-283. https://doi.org/10.1007/s11307017-1118-2

19. Batarseh A, Papadopoulos V (2010) Regulation of translocator protein $18 \mathrm{kDa}$ (TSPO) expression in health and disease states. Mol Cell Endocrinol 327(1-2):1-12. https://doi.org/10.1016/j.mce. 2010.06.013

20. Gatliff J, Campanella M (2016) TSPO: kaleidoscopic 18-kDa amid biochemical pharmacology, control and targeting of mitochondria. Biochem J 473(2):107-121. https://doi.org/10.1042/BJ20150899

21. Papadopoulos V, Amri H, Boujrad N, Cascio C, Culty M, Garnier M, Hardwick M, Li H et al (1997) Peripheral benzodiazepine receptor in cholesterol transport and steroidogenesis. Steroids 62(1): 21-28

22. Veenman L, Vainshtein A, Yasin N, Azrad M, Gavish M (2016) Tetrapyrroles as endogenous TSPO ligands in eukaryotes and 
prokaryotes: comparisons with synthetic ligands. Int J Mol Sci 17(6). https://doi.org/10.3390/ijms17060880

23. Gut P, Zweckstetter M, Banati RB (2015) Lost in translocation: the functions of the $18-\mathrm{kD}$ translocator protein. Trends Endocrinol Metab 26(7):349-356. https://doi.org/10.1016/j.tem.2015.04.001

24. Tu LN, Morohaku K, Manna PR, Pelton SH, Butler WR, Stocco DM, Selvaraj V (2014) Peripheral benzodiazepine receptor/ translocator protein global knock-out mice are viable with no effects on steroid hormone biosynthesis. J Biol Chem 289(40): 27444-27454. https://doi.org/10.1074/jbc.M114.578286

25. Morohaku K, Pelton SH, Daugherty DJ, Butler WR, Deng W, Selvaraj V (2014) Translocator protein/peripheral benzodiazepine receptor is not required for steroid hormone biosynthesis. Endocrinology 155(1):89-97. https://doi.org/10.1210/en.20131556

26. Sileikyte J, Blachly-Dyson E, Sewell R, Carpi A, Menabo R, Di Lisa F, Ricchelli F, Bernardi P et al (2014) Regulation of the mitochondrial permeability transition pore by the outer membrane does not involve the peripheral benzodiazepine receptor (translocator protein of $18 \mathrm{kDa}$ (TSPO)). J Biol Chem 289(20):13769-13781. https://doi.org/10.1074/jbc.M114.549634

27. Li F, Liu J, Liu N, Kuhn LA, Garavito RM, Ferguson-Miller S (2016) Translocator protein $18 \mathrm{kDa}$ (TSPO): an old protein with new functions? Biochemistry 55(20):2821-2831. https://doi.org/ 10.1021/acs.biochem.6b00142

28. Block ML, Zecca L, Hong JS (2007) Microglia-mediated neurotoxicity: uncovering the molecular mechanisms. Nat Rev Neurosci 8(1):57-69. https://doi.org/10.1038/nrn2038

29. Hanisch UK, Kettenmann H (2007) Microglia: active sensor and versatile effector cells in the normal and pathologic brain. Nat Neurosci 10(11):1387-1394. https://doi.org/10.1038/nn1997

30. Choi J, Ifuku M, Noda M, Guilarte TR (2011) Translocator protein $(18 \mathrm{kDa}) /$ peripheral benzodiazepine receptor specific ligands induce microglia functions consistent with an activated state. Glia 59(2):219-230. https://doi.org/10.1002/glia.21091

31. Singel KL, Segal BH (2016) NOX2-dependent regulation of inflammation. Clin Sci (Lond) 130(7):479-490. https://doi.org/10. 1042/CS20150660

32. Sorce S, Krause KH (2009) NOX enzymes in the central nervous system: from signaling to disease. Antioxid Redox Signal 11(10): 2481-2504. https://doi.org/10.1089/ARS.2009.2578

33. Yu L, Zhen L, Dinauer MC (1997) Biosynthesis of the phagocyte NADPH oxidase cytochrome b558. Role of heme incorporation and heterodimer formation in maturation and stability of gp91phox and p22phox subunits. J Biol Chem 272(43):27288-27294

34. Yu L, Quinn MT, Cross AR, Dinauer MC (1998) Gp91(phox) is the heme binding subunit of the superoxide-generating NADPH oxidase. Proc Natl Acad Sci U S A 95(14):7993-7998

35. Yu L, DeLeo FR, Biberstine-Kinkade KJ, Renee J, Nauseef WM, Dinauer MC (1999) Biosynthesis of flavocytochrome b558. gp91(phox) is synthesized as a $65-\mathrm{kDa}$ precursor (p65) in the endoplasmic reticulum. J Biol Chem 274(7):4364-4369

36. DeLeo FR, Burritt JB, Yu L, Jesaitis AJ, Dinauer MC, Nauseef WM (2000) Processing and maturation of flavocytochrome b558 include incorporation of heme as a prerequisite for heterodimer assembly. $\mathrm{J}$ Biol Chem 275(18):13986-13993

37. DeLeo FR, Quinn MT (1996) Assembly of the phagocyte NADPH oxidase: molecular interaction of oxidase proteins. J Leukoc Biol 60(6):677-691

38. Shao D, Segal AW, Dekker LV (2003) Lipid rafts determine efficiency of NADPH oxidase activation in neutrophils. FEBS Lett 550(1-3):101-106

39. Vilhardt F, van Deurs B (2004) The phagocyte NADPH oxidase depends on cholesterol-enriched membrane microdomains for assembly. EMBO J 23(4):739-748. https://doi.org/10.1038/sj.emboj. 7600066
40. Giulian D, Baker TJ (1986) Characterization of ameboid microglia isolated from developing mammalian brain. J Neurosci 6(8):21632178

41. Gordon R, Hogan CE, Neal ML, Anantharam V, Kanthasamy AG, Kanthasamy A (2011) A simple magnetic separation method for high-yield isolation of pure primary microglia. J Neurosci Methods 194(2):287-296. https://doi.org/10.1016/j.jneumeth. 2010.11.001

42. Ryder E, Doe B, Gleeson D, Houghton R, Dalvi P, Grau E, Habib B, Miklejewska E et al (2014) Rapid conversion of EUCOMM/ KOMP-CSD alleles in mouse embryos using a cell-permeable Cre recombinase. Transgenic Res 23(1):177-185. https://doi.org/10. 1007/s11248-013-9764-x

43. Miao B, Degterev A (2009) Methods to analyze cellular necroptosis. Methods Mol Biol 559:79-93. https://doi.org/10. 1007/978-1-60327-017-5 6

44. Brewer LD, Thibault O, Staton J, Thibault V, Rogers JT, GarciaRamos G, Kraner S, Landfield PW et al (2007) Increased vulnerability of hippocampal neurons with age in culture: temporal association with increases in NMDA receptor current, NR2A subunit expression and recruitment of L-type calcium channels. Brain Res 1151:20-31. https://doi.org/10.1016/j.brainres.2007.03.020

45. Schmittgen TD, Livak KJ (2008) Analyzing real-time PCR data by the comparative C(T) method. Nat Protoc 3(6):1101-1108

46. Stansfield KH, Pilsner JR, Lu Q, Wright RO, Guilarte TR (2012) Dysregulation of BDNF-TrkB signaling in developing hippocampal neurons by $\mathrm{Pb}(2+)$ : implications for an environmental basis of neurodevelopmental disorders. Toxicol Sci 127(1):277-295. https://doi.org/10.1093/toxsci/kfs090

47. Loth MK, Choi J, McGlothan JL, Pletnikov MV, Pomper MG, Guilarte TR (2016) TSPO in a murine model of Sandhoff disease: presymptomatic marker of neurodegeneration and disease pathophysiology. Neurobiol Dis 85:174-186. https://doi.org/10.1016/j. nbd.2015.11.001

48. Waterhouse A, Bertoni M, Bienert S, Studer G, Tauriello G, Gumienny R, Heer FT, de Beer TAP et al (2018) SWISS-MODEL: homology modelling of protein structures and complexes. Nucleic Acids Res 46(W1):W296-W303. https://doi.org/10.1093/nar/gky427

49. Madeira F, Park YM, Lee J, Buso N, Gur T, Madhusoodanan N, Basutkar P, Tivey ARN et al (2019) The EMBL-EBI search and sequence analysis tools APIs in 2019. Nucleic Acids Res 47(W1): W636-W641. https://doi.org/10.1093/nar/gkz268

50. Liu R, Hu J (2011) Computational prediction of heme-binding residues by exploiting residue interaction network. PLoS One 6(10): e25560. https://doi.org/10.1371/journal.pone.0025560

51. Gatliff J, East DA, Singh A, Alvarez MS, Frison M, Matic I, Ferraina C, Sampson N et al (2017) A role for TSPO in mitochondrial $\mathrm{Ca}(2+)$ homeostasis and redox stress signaling. Cell Death Dis 8(6):e2896. https://doi.org/10.1038/cddis.2017.186

52. McEnery MW, Snowman AM, Trifiletti RR, Snyder SH (1992) Isolation of the mitochondrial benzodiazepine receptor: association with the voltage-dependent anion channel and the adenine nucleotide carrier. Proc Natl Acad Sci U S A 89(8):3170-3174

53. Soderberg O, Gullberg M, Jarvius M, Ridderstrale K, Leuchowius KJ, Jarvius J, Wester K, Hydbring P et al (2006) Direct observation of individual endogenous protein complexes in situ by proximity ligation. Nat Methods 3(12):995-1000. https://doi.org/10.1038/nmeth947

54. Weibrecht I, Leuchowius KJ, Clausson CM, Conze T, Jarvius M, Howell WM, Kamali-Moghaddam M, Soderberg O (2010) Proximity ligation assays: a recent addition to the proteomics toolbox. Expert Rev Proteomics 7(3):401-409. https://doi.org/10.1586/epr.10.10

55. Guilarte TR, Loth MK, Guariglia SR (2016) TSPO finds NOX2 in microglia for redox homeostasis. Trends Pharmacol Sci 37(5):334 343. https://doi.org/10.1016/j.tips.2016.02.008 
56. Olson JM, Ciliax BJ, Mancini WR, Young AB (1988) Presence of peripheral-type benzodiazepine binding sites on human erythrocyte membranes. Eur J Pharmacol 152(1-2):47-53

57. Woods MJ, Williams DC (1996) Multiple forms and locations for the peripheral-type benzodiazepine receptor. Biochem Pharmacol 52(12):1805-1814

58. Jeyakumar M, Smith DA, Williams IM, Borja MC, Neville DC, Butters TD, Dwek RA, Platt FM (2004) NSAIDs increase survival in the Sandhoff disease mouse: synergy with N-butyldeoxynojirimycin. Ann Neurol 56(5):642-649. https://doi.org/10.1002/ana.20242

59. Layer G, Reichelt J, Jahn D, Heinz DW (2010) Structure and function of enzymes in heme biosynthesis. Protein Sci 19(6):11371161. https://doi.org/10.1002/pro.405

60. Brown DI, Griendling KK (2009) Nox proteins in signal transduction. Free Radic Biol Med 47(9):1239-1253. https://doi.org/10. 1016/j.freeradbiomed.2009.07.023

61. Paillusson S, Stoica R, Gomez-Suaga P, Lau DHW, Mueller S, Miller T, Miller CCJ (2016) There's something wrong with my MAM; the ER-mitochondria axis and neurodegenerative diseases. Trends Neurosci 39(3):146-157. https://doi.org/10.1016/j.tins.2016.01.008

62. Jaremko L, Jaremko M, Giller K, Becker S, Zweckstetter M (2014) Structure of the mitochondrial translocator protein in complex with a diagnostic ligand. Science 343(6177):1363-1366. https://doi.org/ $10.1126 /$ science. 1248725

63. Jaremko M, Jaremko Ł, Jaipuria G, Becker S, Zweckstetter M (2015) Structure of the mammalian TSPO/PBR protein. Biochem Soc Trans 43(4):566-571. https://doi.org/10.1042/bst20150029

64. Jaremko M, Jaremko Ł, Giller K, Becker S, Zweckstetter M (2015) Structural integrity of the A147T polymorph of mammalian TSPO. ChemBioChem 16(10):1483-1489. https://doi.org/10.1002/cbic. 201500217

65. Li F, Liu J, Zheng Y, Garavito RM, Ferguson-Miller S (2015) Crystal structures of translocator protein (TSPO) and mutant mimic of a human polymorphism. Science 347(6221):555-558. https:// doi.org/10.1126/science. 1260590

66. Li T, Bonkovsky HL, Guo J-t (2011) Structural analysis of heme proteins: implications for design and prediction. BMC Struct Biol 11(1):13. https://doi.org/10.1186/1472-6807-11-13

67. Taketani S, Kohno H, Okuda M, Furukawa T, Tokunaga R (1994) Induction of peripheral-type benzodiazepine receptors during differentiation of mouse erythroleukemia cells. A possible involvement of these receptors in heme biosynthesis. J Biol Chem 269(10):7527-7531

68. Zhao AH, Tu LN, Mukai C, Sirivelu MP, Pillai VV, Morohaku K, Cohen R, Selvaraj V (2016) Mitochondrial translocator protein (TSPO) function is not essential for heme biosynthesis. J Biol Chem 291(4):1591-1603. https://doi.org/10.1074/jbc.M115.686360

69. Shimoyama S, Furukawa T, Ogata Y, Nikaido Y, Koga K, Sakamoto Y, Ueno S, Nakamura K (2019) Lipopolysaccharide induces mouse translocator protein $(18 \mathrm{kDa})$ expression via the AP-1 complex in the microglial cell line, BV-2. PLoS One 14(9): e0222861. https://doi.org/10.1371/journal.pone.0222861

70. Timmerman R, Burm SM, Bajramovic JJ (2018) An overview of in vitro methods to study microglia. Front Cell Neurosci 12:242. https://doi.org/10.3389/fncel.2018.00242

71. He Y, Yao X, Taylor N, Bai Y, Lovenberg T, Bhattacharya A (2018) RNA sequencing analysis reveals quiescent microglia isolation methods from postnatal mouse brains and limitations of BV2 cells. J Neuroinflammation 15(1):153. https://doi.org/10.1186/s12974018-1195-4

72. Stansley B, Post J, Hensley K (2012) A comparative review of cell culture systems for the study of microglial biology in Alzheimer's disease. J Neuroinflammation 9:115. https://doi.org/10.1186/17422094-9-115
73. Bronstein R, Torres L, Nissen JC, Tsirka SE (2013) Culturing microglia from the neonatal and adult central nervous system. J Vis Exp 78:50647. https://doi.org/10.3791/50647

74. Lambeth JD (2004) NOX enzymes and the biology of reactive oxygen. Nat Rev Immunol 4(3):181-189. https://doi.org/10.1038/ nri1312

75. Katsuyama M (2010) NOX/NADPH oxidase, the superoxidegenerating enzyme: its transcriptional regulation and physiological roles. J Pharmacol Sci 114(2):134-146

76. Wolf A, Herb M, Schramm M, Langmann T (2020) The TSPO-NOX1 axis controls phagocyte-triggered pathological angiogenesis in the eye. Nat Commun 11(1):2709. https://doi.org/10.1038/s41467-020-16400-8

77. Taketani S, Kohno H, Furukawa T, Tokunaga R (1995) Involvement of peripheral-type benzodiazepine receptors in the intracellular transport of heme and porphyrins. J Biochem 117(4):875-880

78. Verma A, Nye JS, Snyder SH (1987) Porphyrins are endogenous ligands for the mitochondrial (peripheral-type) benzodiazepine receptor. Proc Natl Acad Sci U S A 84(8):2256-2260

79. Papadopoulos V, Lecanu L, Brown RC, Han Z, Yao ZX (2006) Peripheral-type benzodiazepine receptor in neurosteroid biosynthesis, neuropathology and neurological disorders. Neuroscience 138(3):749 756. https://doi.org/10.1016/j.neuroscience.2005.05.063

80. Asagami H, Hino Y, Kang D, Minakami S, Takeshige K (1994) Preferential heme transport through endoplasmic reticulum associated with mitochondria in rat liver. Biochim Biophys Acta 1193(2):345-352

81. Nakazawa F, Alev C, Shin M, Nakaya Y, Jakt LM, Sheng G (2009) PBRL, a putative peripheral benzodiazepine receptor, in primitive erythropoiesis. Gene Expr Patterns 9(2):114-121. https://doi.org/ 10.1016/j.gep.2008.09.005

82. Shayeghi M, Latunde-Dada GO, Oakhill JS, Laftah AH, Takeuchi K, Halliday N, Khan Y, Warley A et al (2005) Identification of an intestinal heme transporter. Cell 122(5):789-801. https://doi.org/10. 1016/j.cell.2005.06.025

83. Huntley TE, Strittmatter P (1972) The effect of heme binding on the tryptophan residue and the protein conformation of cytochrome $b 5$. J Biol Chem 247(14):4641-4647

84. Kim HJ, Khalimonchuk O, Smith PM, Winge DR (2012) Structure, function, and assembly of heme centers in mitochondrial respiratory complexes. Biochimica et Biophysica Acta (BBA) - Molecular Cell Research 1823(9):1604-1616. https://doi.org/10.1016/j.bbamcr. 2012.04.008

85. Komatsu T, Matsukawa Y, Tsuchida E (2002) Effect of heme structure on O2-binding properties of human serum albumin-heme hybrids: intramolecular histidine coordination provides a stable $\mathrm{O} 2$ -adduct complex. Bioconjug Chem 13(3):397-402. https://doi. org/10.1021/bc010067r

86. Bocahut A, Derrien V, Bernad S, Sebban P, Sacquin-Mora S, Guittet E, Lescop E (2013) Heme orientation modulates histidine dissociation and ligand binding kinetics in the hexacoordinated human neuroglobin. JBIC Journal of Biological Inorganic Chemistry 18(1):111-122. https://doi.org/10.1007/s00775-012-0956-2

87. Vanhee C, Zapotoczny G, Masquelier D, Ghislain M, Batoko H (2011) The Arabidopsis multistress regulator TSPO is a heme binding membrane protein and a potential scavenger of porphyrins via an autophagy-dependent degradation mechanism. Plant Cell 23(2): 785-805. https://doi.org/10.1105/tpc.110.081570

88. Hachez C, Veljanovski V, Reinhardt H, Guillaumot D, Vanhee C, Chaumont F, Batoko H (2014) The Arabidopsis abiotic stressinduced TSPO-related protein reduces cell-surface expression of the aquaporin PIP2;7 through protein-protein interactions and autophagic degradation. Plant Cell 26(12):4974-4990. https://doi.org/ $10.1105 /$ tpc. 114.134080

Publisher's Note Springer Nature remains neutral with regard to jurisdictional claims in published maps and institutional affiliations. 